زكي عبد المعطي أبو زيادةٌ إيناس موسى الزين

المجلد الرابع عشر العدد (50) 2021م إئاسن موسى الزين

أثر الرشـافة الاســتراتيصية في تعزيـز التوصه الريادي

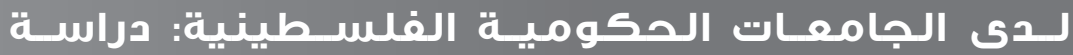
ميدانية تصليلية الفية الفلية

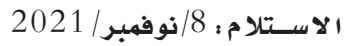

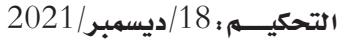

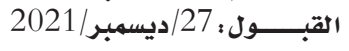

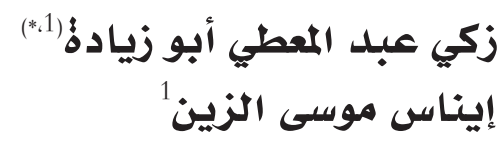

(C) 2021 University of Science and Technology, Yemen. This article can be distributed under the terms of the Creative Commons Attribution License, which permits unrestricted use, distribution, and reproduction in any medium, provided the original author and source are credited.

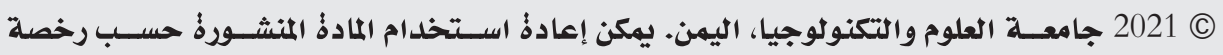
مؤسسة المشاع الإبلاعي شريطة الاستشهاد بالمؤلف والمجلة. 


\section{أثر الرشاقة الاستراتيجية في تعزيز التوجه الريادي لدى الجامعات الحكومية الفلسطينية: دراسة ميدانية تحليلية}

\section{الملخص:}

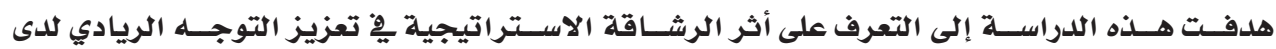

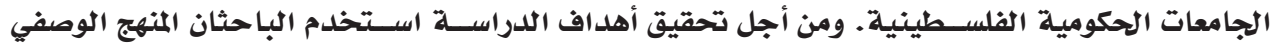

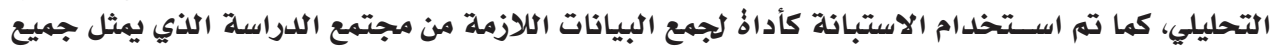

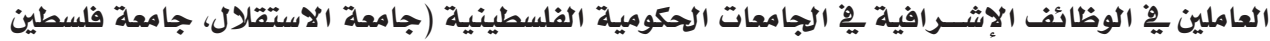

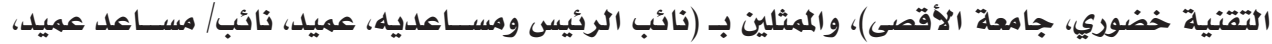

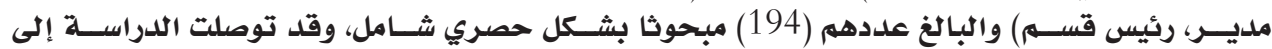

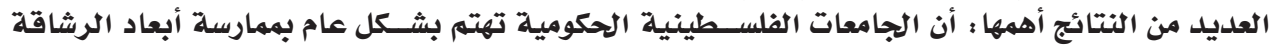

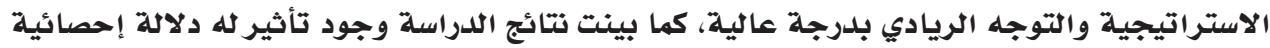

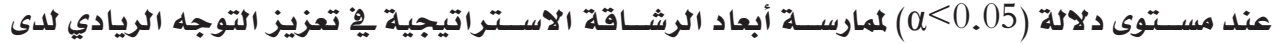

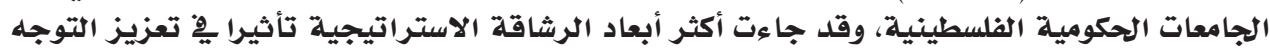

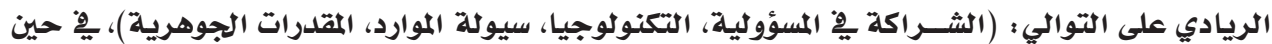

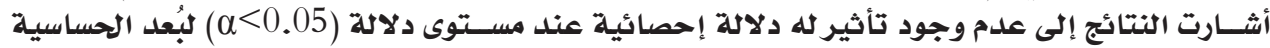

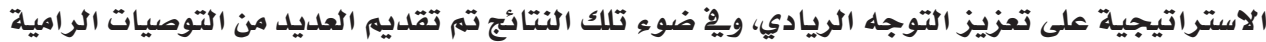

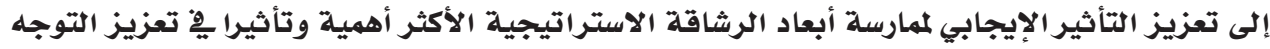

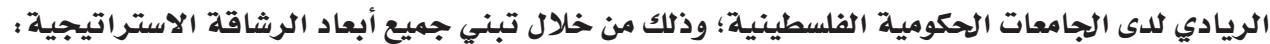

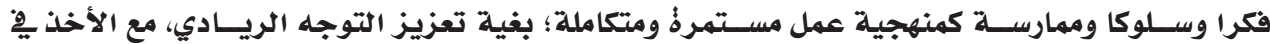
الاعتبار كافة المقومات التي تلدعم ذلك.

الكلمات المفتاحية : الرشاقة الاستراتيجية، التوجه الريادي، الجامعات الحكومية الفلسطينية. 


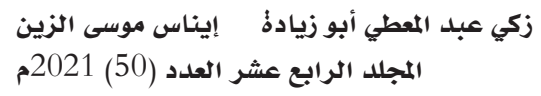

\title{
The Impact of Strategic Agility in Enhancing the Entrepreneurial Orientation at Palestinian Public Universities: An Analytical Field Study
}

\begin{abstract}
:
The study aimed at identifying the impact of strategic agility in enhancing the entrepreneurial orientation at Palestinian public universities. To achieve this, the descriptive analytical method was adopted, and a questionnaire was used to collect data from the study sample, which consisted of (194) respondents who were selected by the complete census method. The sample represented all the staff in the supervisory jobs among Palestinian public universities (Al Istiqlal University, Palestine Technical University-Kadoorie, Al- Aqsa University). The jobs covered vice president and his assistants, dean, vice dean, manager, the head of department. The study results revealed that the Palestinian Universities are generally concerned with practicing dimensions of the strategic agility and the entrepreneurial orientation at a high degree. There was a statistically significant difference $(\alpha<0.05)$ of practicing the dimensions of the strategic agility to promote the entrepreneurial orientation for the Palestinian public universities. The most effective dimensions of strategic agility on the entrepreneurial orientation were partnership of responsibility, technology, resource liquidity and substantial assets. On the other hand, there were no statistically significant differences $(\alpha<0.05)$ of the strategic sensitivity dimension on promoting entrepreneurial orientation. The study recommended adopting all dimensions of strategic agility as a work methodology for Palestinian Public Universities in order to strengthen the entrepreneurial orientation, considering all the elements that support it.
\end{abstract}

Keywords: strategic agility, entrepreneurial orientation, Palestinian public universities. 


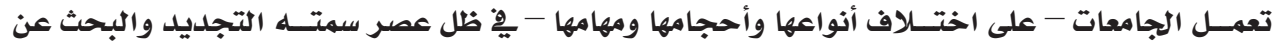

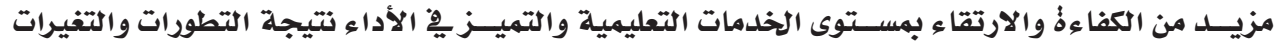

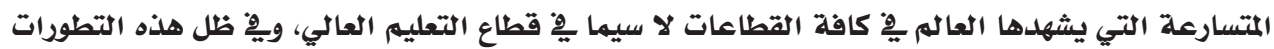

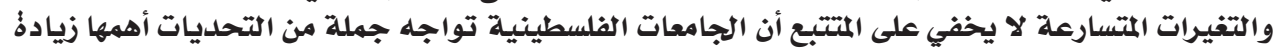

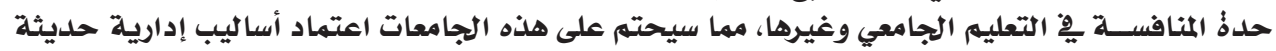

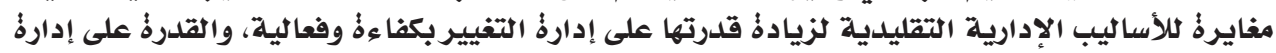

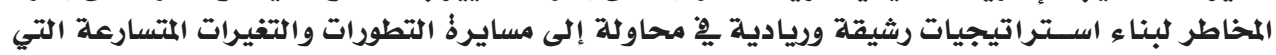

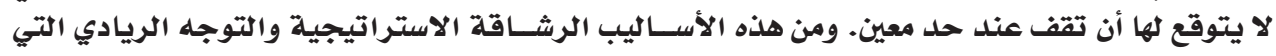

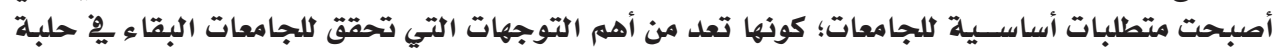

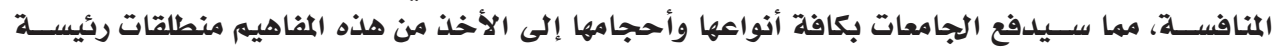

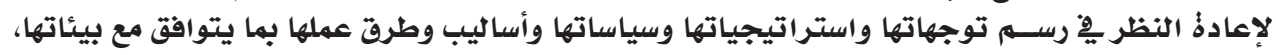

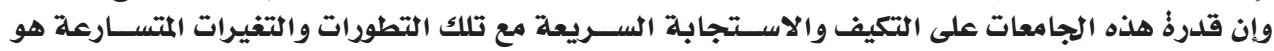

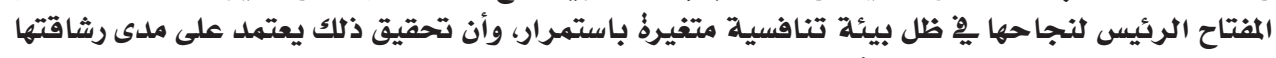

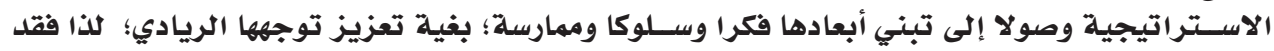

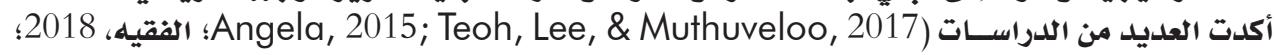

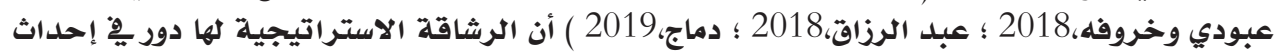

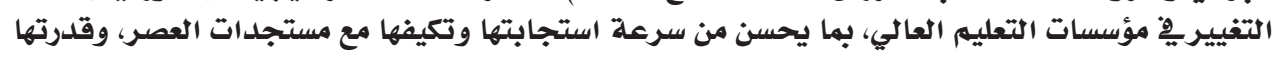

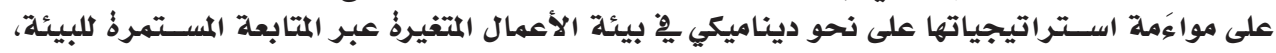

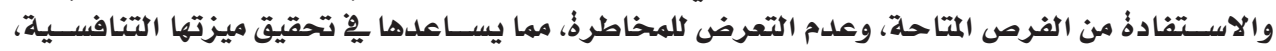

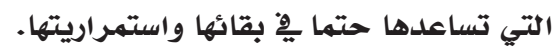

Oni, Agbobli, \& Iwu, 2019; García-) وعلـى الجانب الآخـر، فقد أثبتت العديد من الدراســات Villaverde, Rodrigo-Alarcón, Parra-Requena, \& Ruiz-Ortega, 2018; Chavez, Yu, Jacobs, \& Feng, 2017; Amin, Thurasamy, Aldakhil, \& Kaswuri, 2016; Yoon, 2012)، أن التوجه الريادي يشكل عنصرا رئيسا للنجاح التتظيمي، والوصول إلى مستويات الأداء المتميز ألتيز

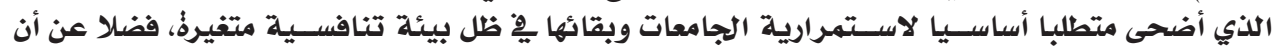

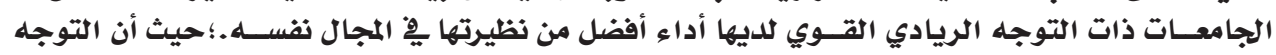

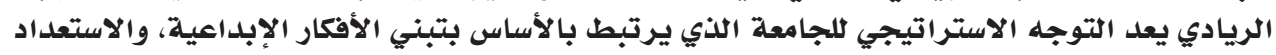

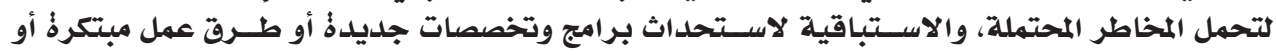

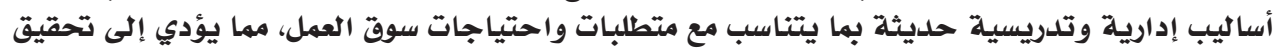

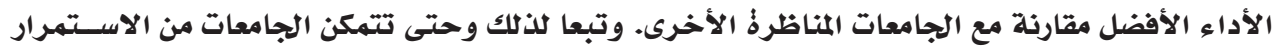

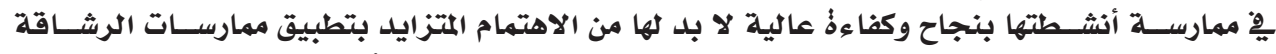

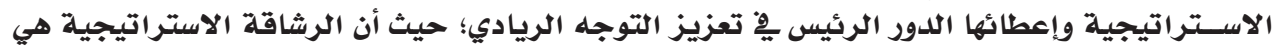

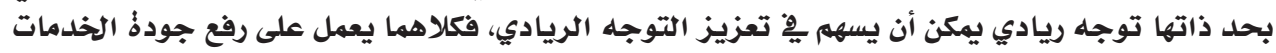

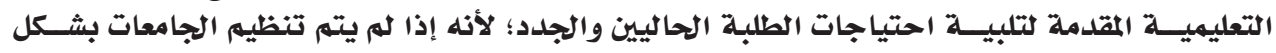

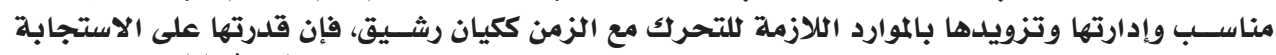

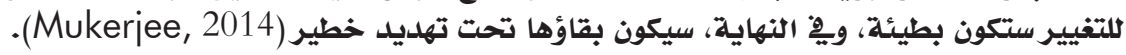

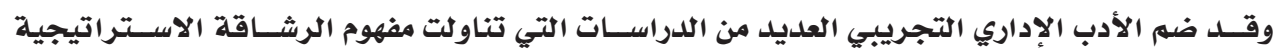

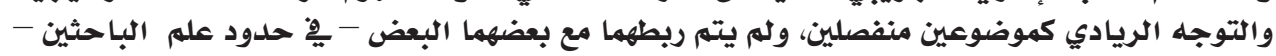

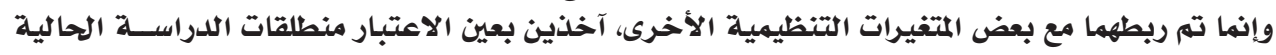




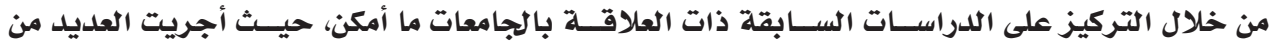

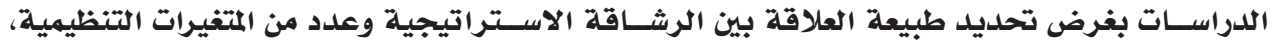

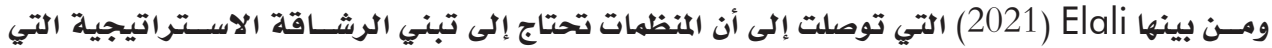

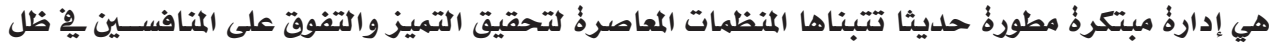

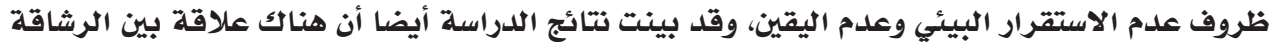

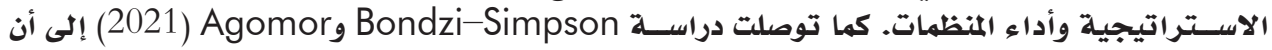

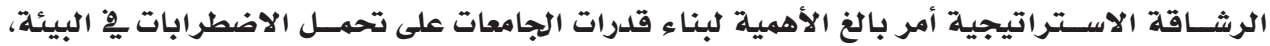

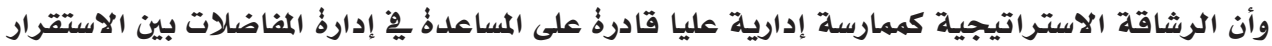

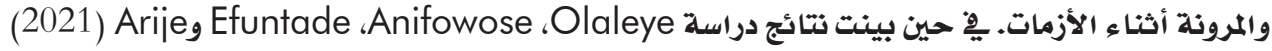

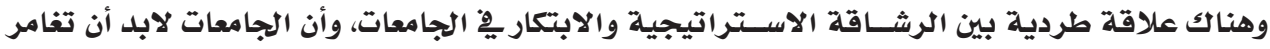

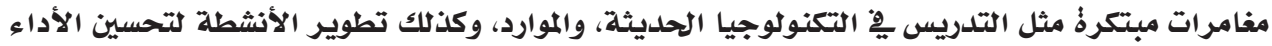

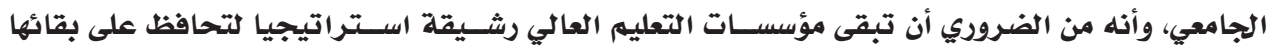

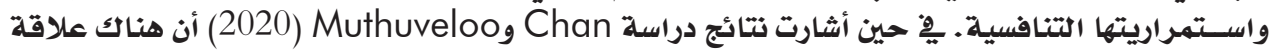

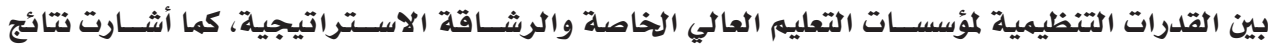

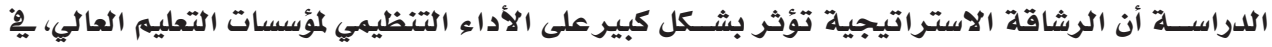

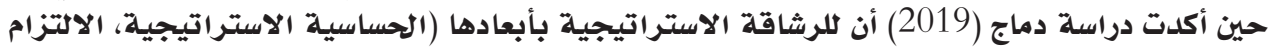

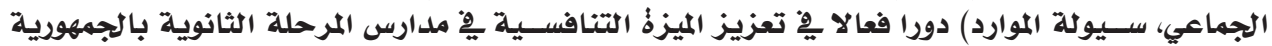

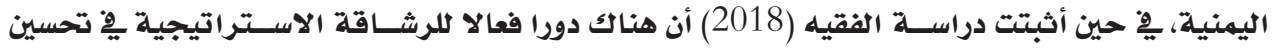

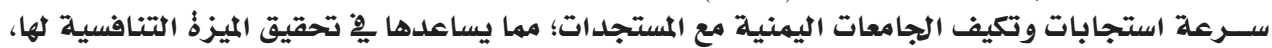

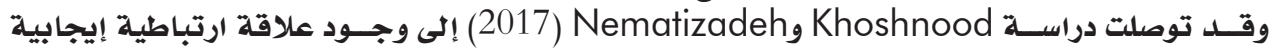

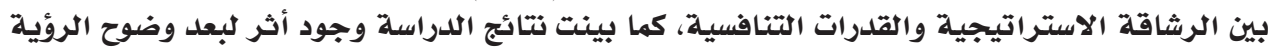

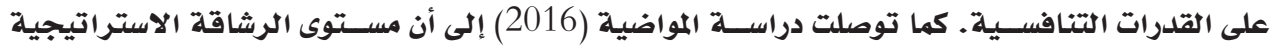

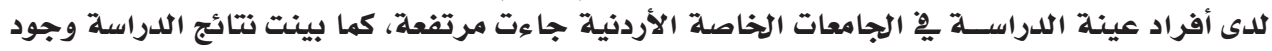

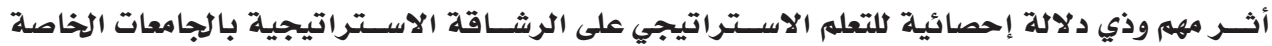

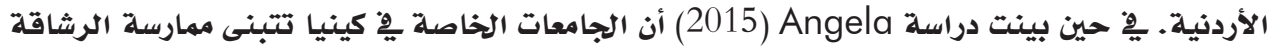

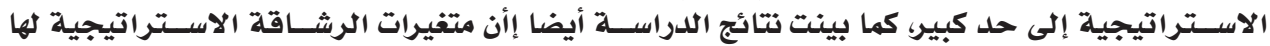

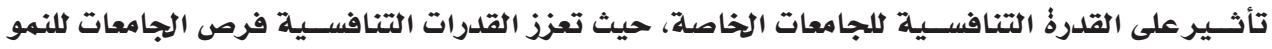

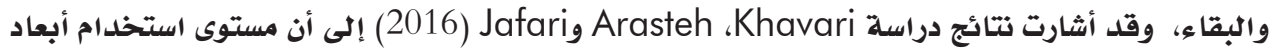

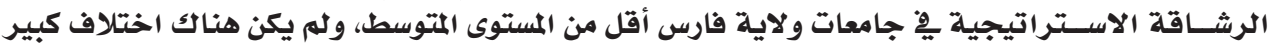

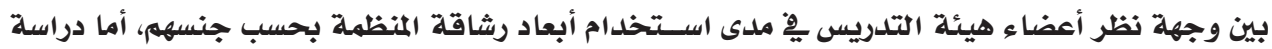
لجاتج Mukerjee

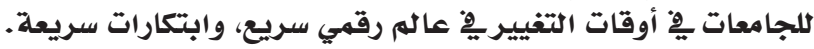

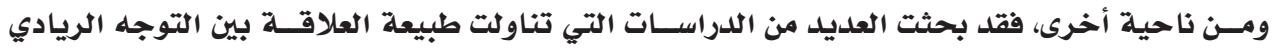

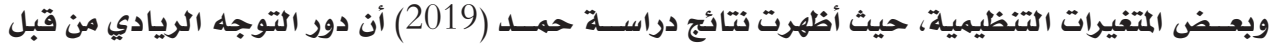

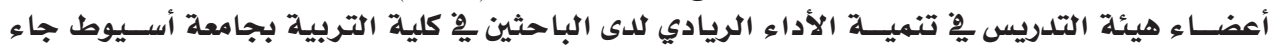

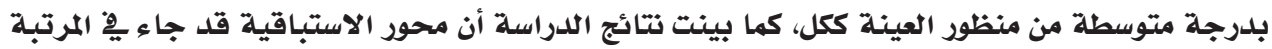

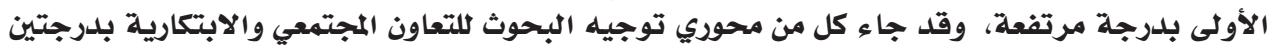

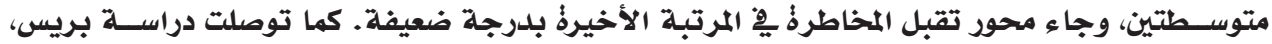

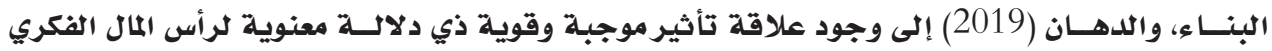

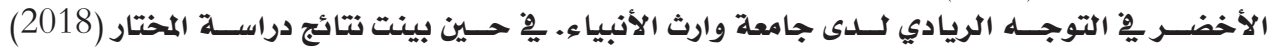

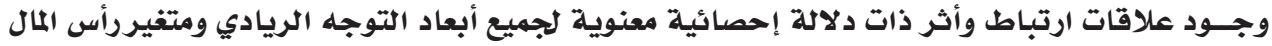

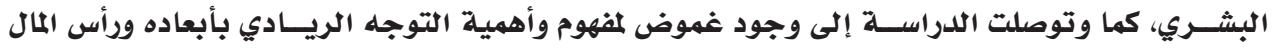




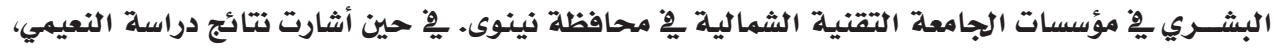

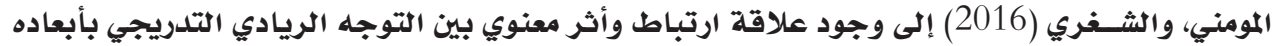

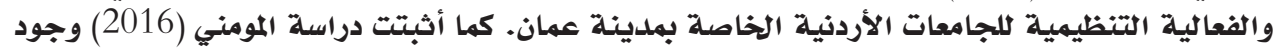

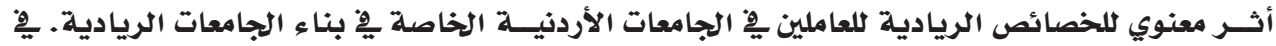

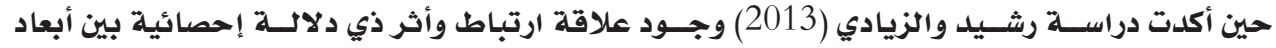

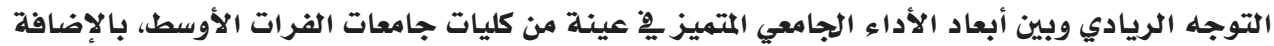

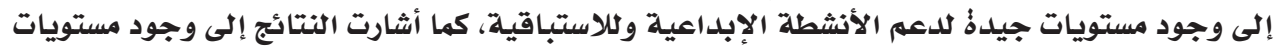

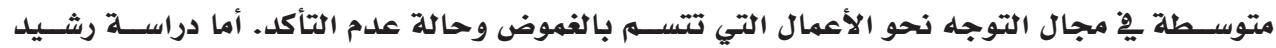

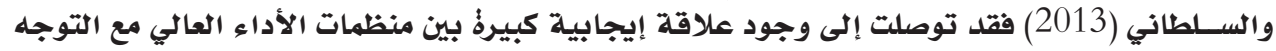

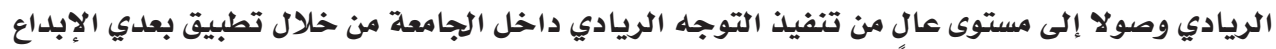

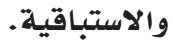

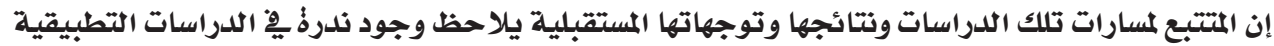

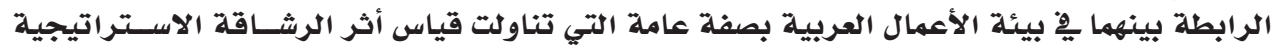

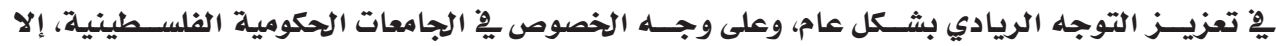

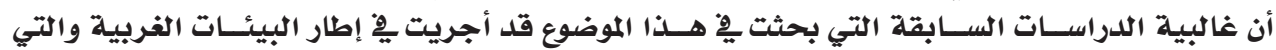

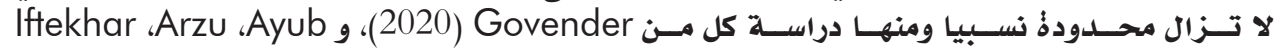

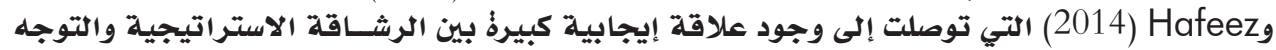

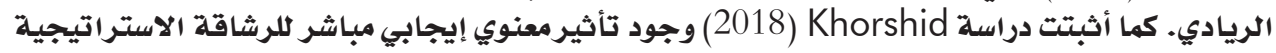

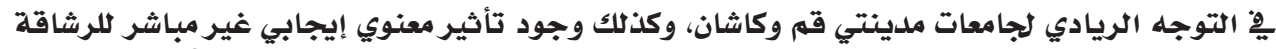

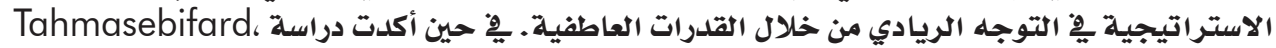

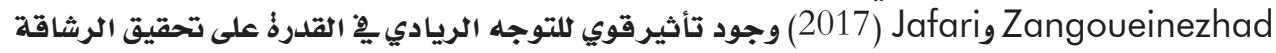

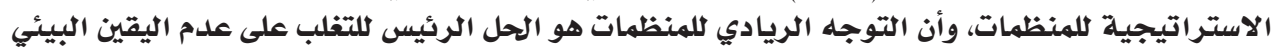

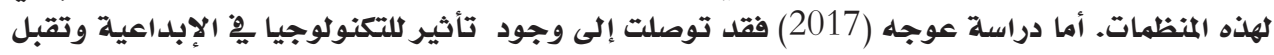

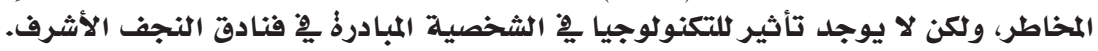

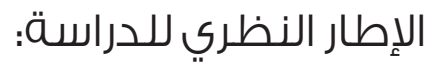

أولا: مفهوم الرشاقة الاستراتيجية :

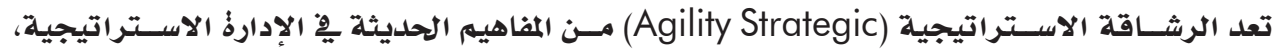

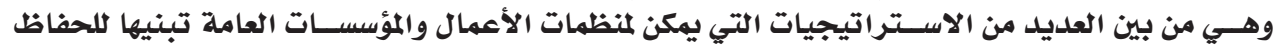

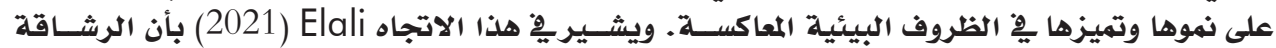

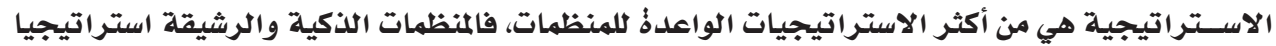

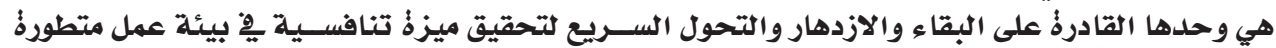

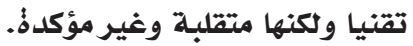

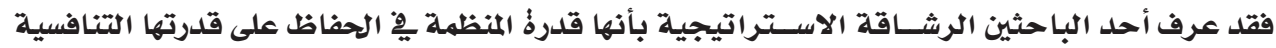

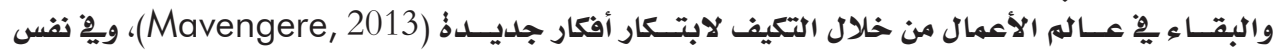

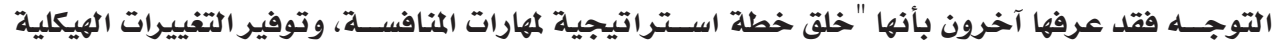

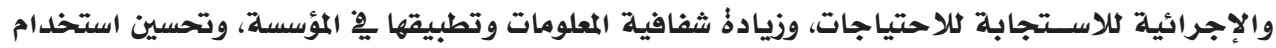

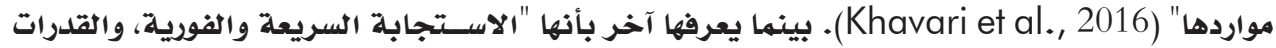

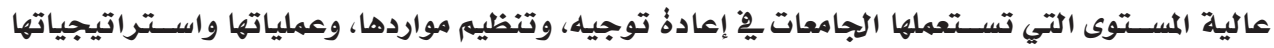

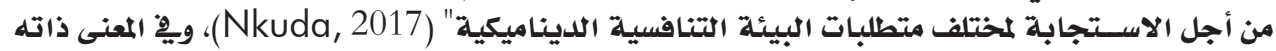

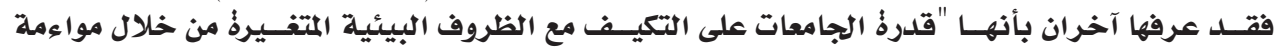




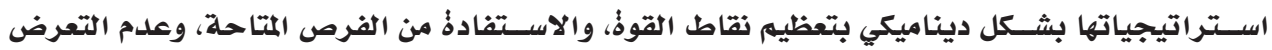

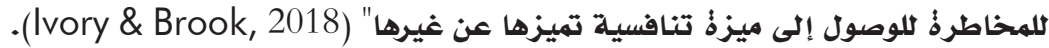

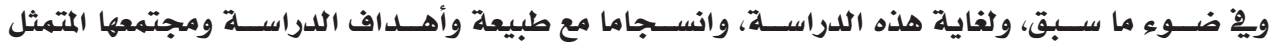

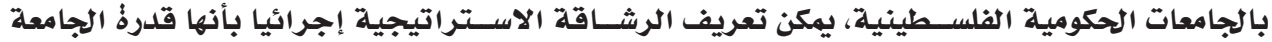

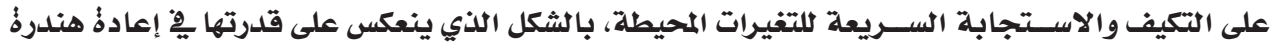

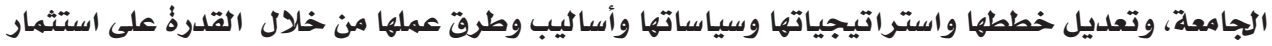

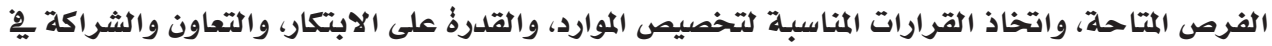

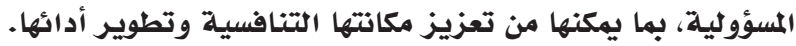
أبعاد الرشاقة الاستراتيجية ؛

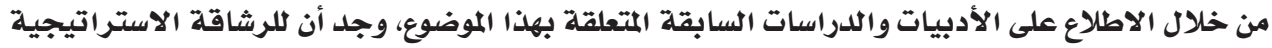

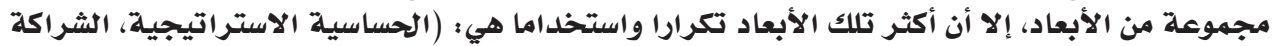

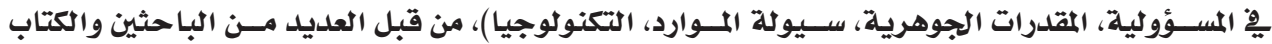

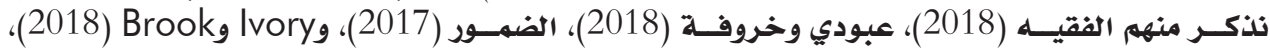
و Mavengere

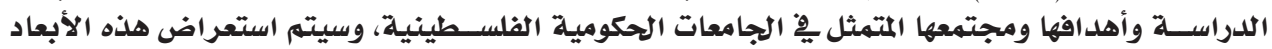

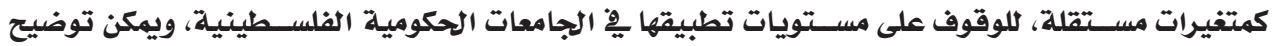

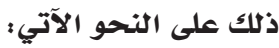

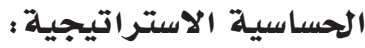

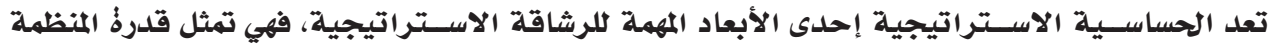

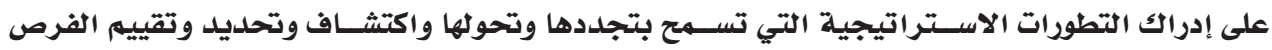

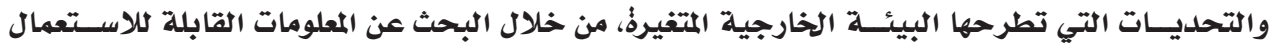

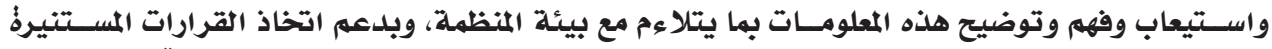

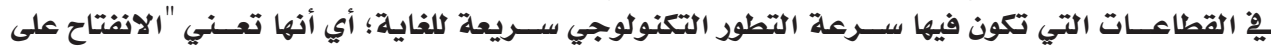

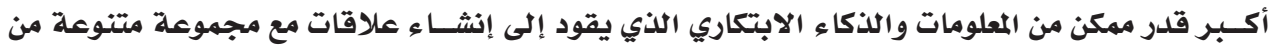

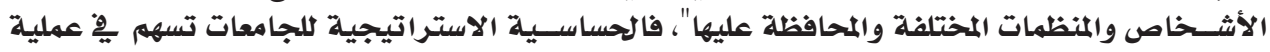

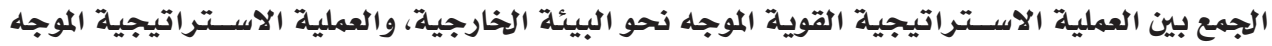

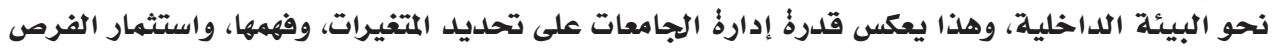

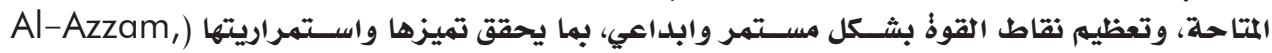
Irtaimeh, \& Khaddam, 2017; Prats, Siota, Gillespie, \& Singleton, 2018; Ivory \& .(Brook, 2018; Lewis, Andriopoulos, \& Smith, 2014; Mavengere, 2013

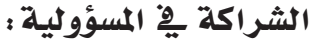

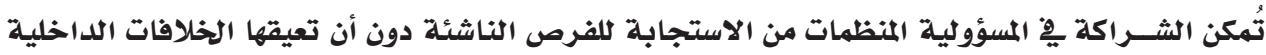

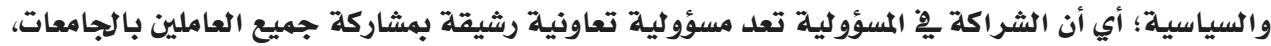

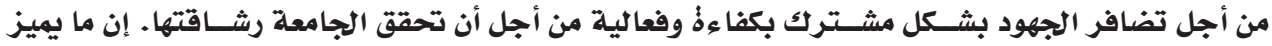

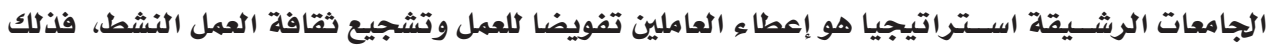

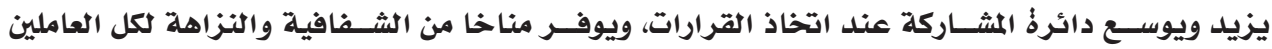

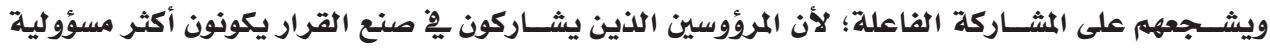

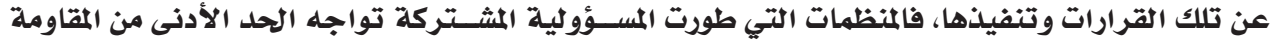

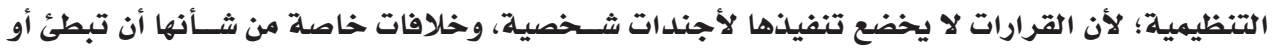

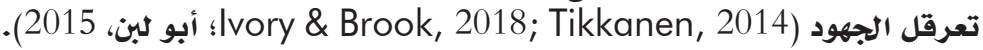


المقلدرات الجوهريـة ؛

المقدرات الجوهرية هي المهارات الخاصة بالمنظمات، والسمات المعرفية نحو تحقيق أعلى المستويات الممكنة

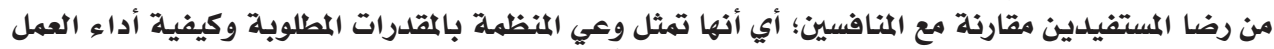

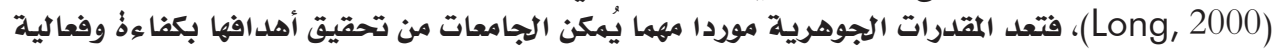

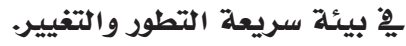
سيولة الموارد :

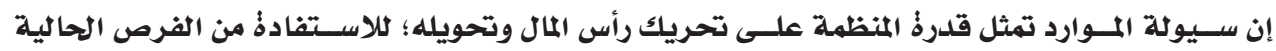

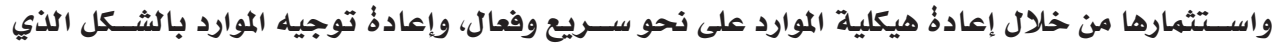

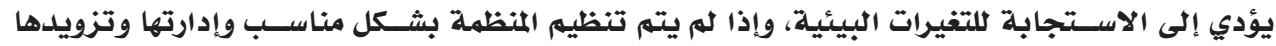

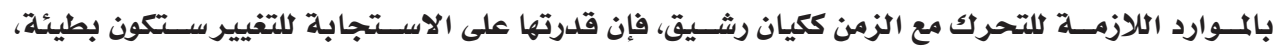

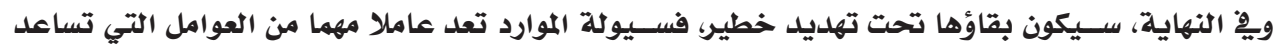

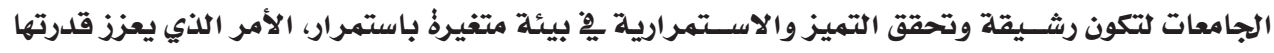

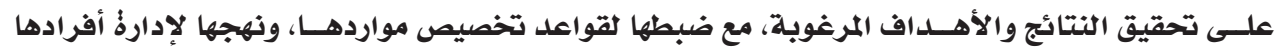
.(Aqilat, 2019; Mukerjee, 2014; Tikkanen, 2014; Doz \& Kosonen, 2010)

التنكنولوجيا :

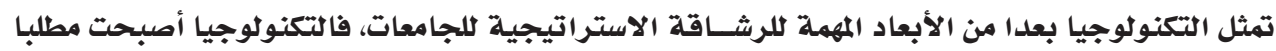

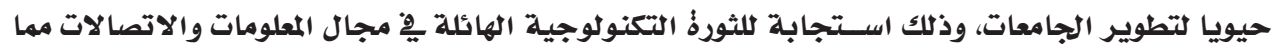

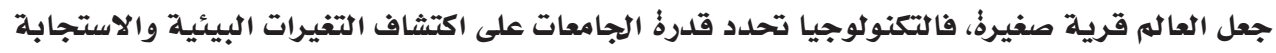

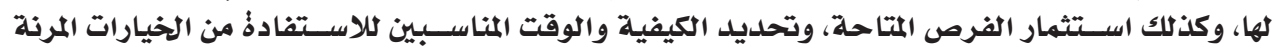

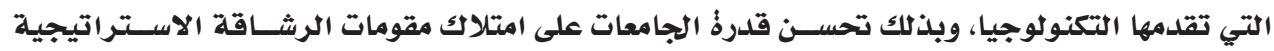

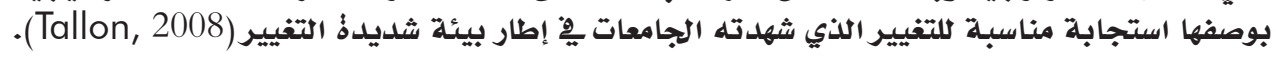

ثانيا: مفهوم التوجه الريادي:

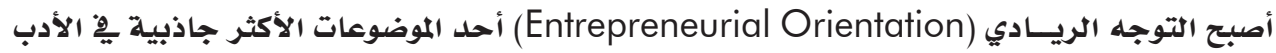

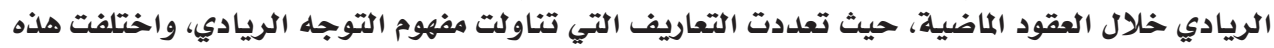

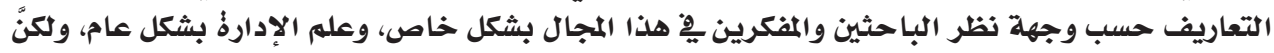

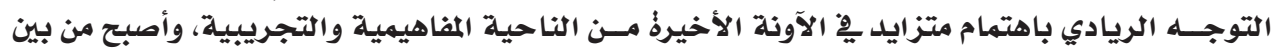

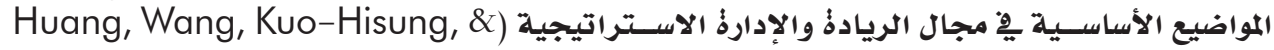

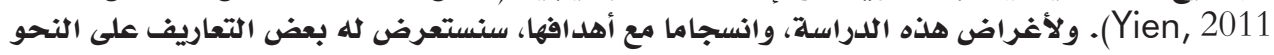
الآتي:

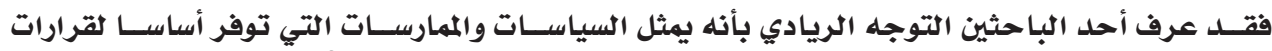

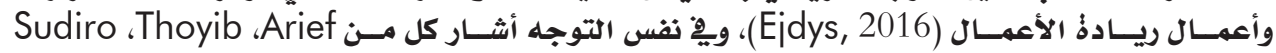

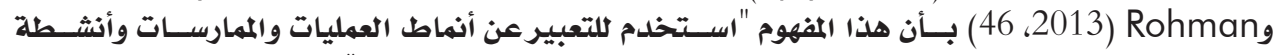

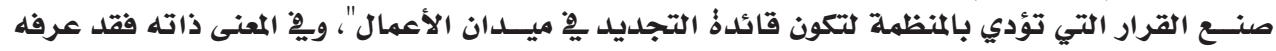

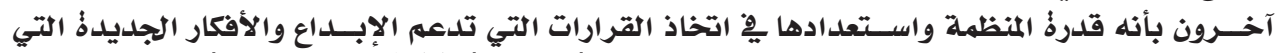

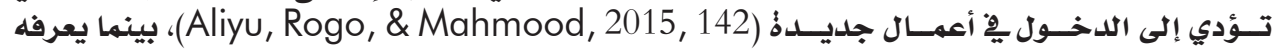

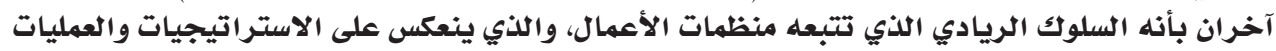

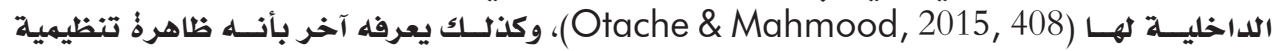

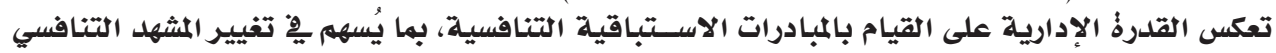

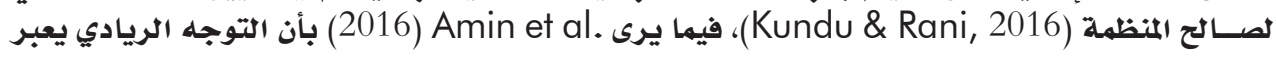




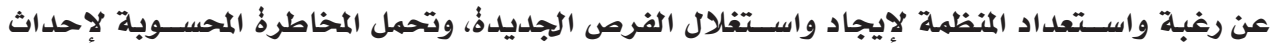

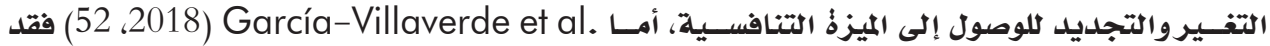

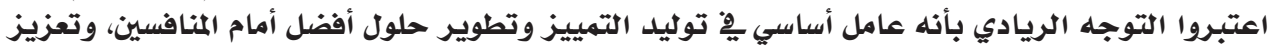

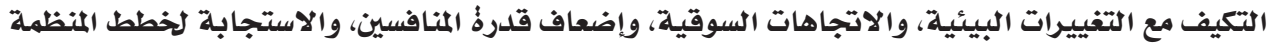

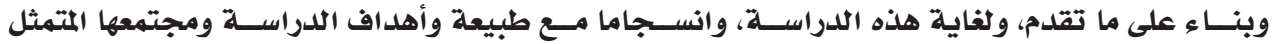

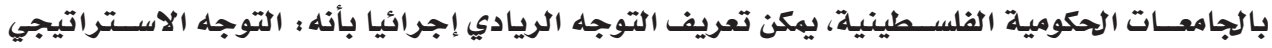

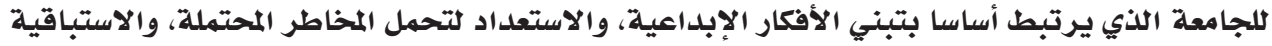

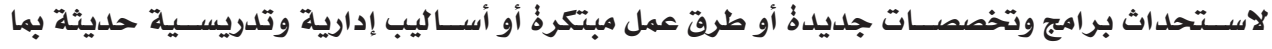

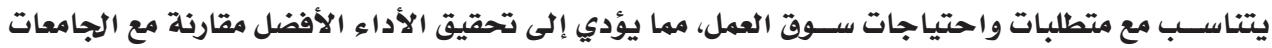

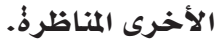
أبعاد التوجه الريادي :

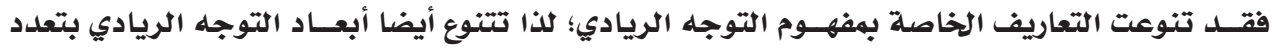

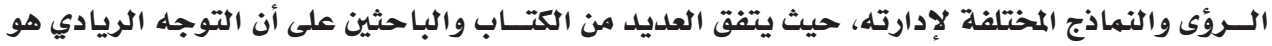

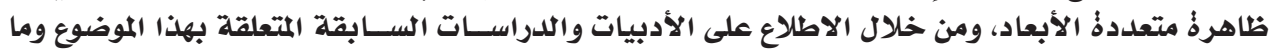

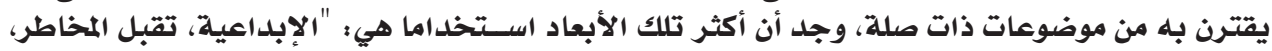

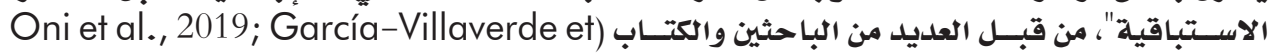
al., 2018; Al-Dhaafri, Al-Swidi, \& Yusoff, 2016; Faiz \& Ahmad, 2015; Osman, Rashid, Ahmad, \& Hussain, 2011; Clercq, Dimov, \& Thongpapanl, 2010; Pearce, Fritz, \& Davis, 2010; Hughes \& Morgan, 2007; Kropp, Lindsay, \& Shoham, 2006; واعتمـادا على ذلك، يتقـق الباحثان مع وجهة نظر هؤلاء الباحثين (Wiklund \& Shepherd, 2005

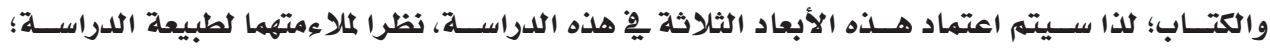

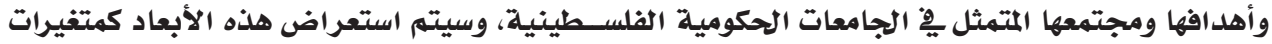

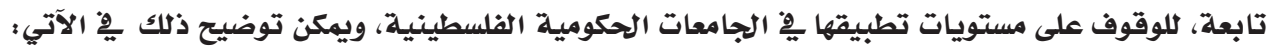

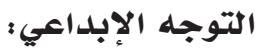

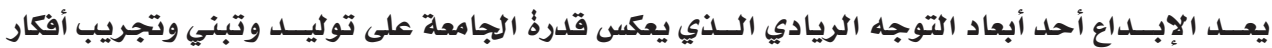

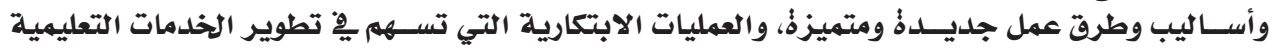

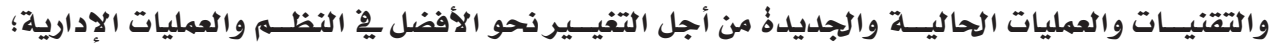

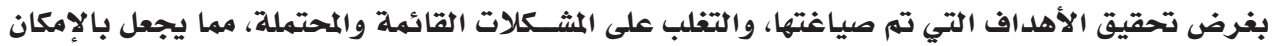

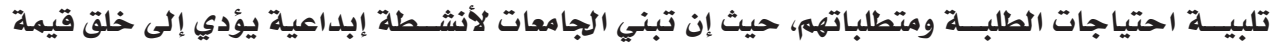

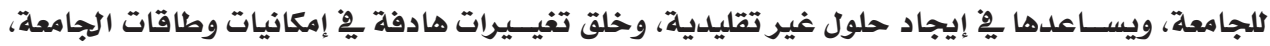

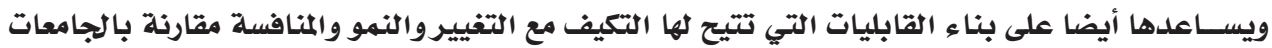

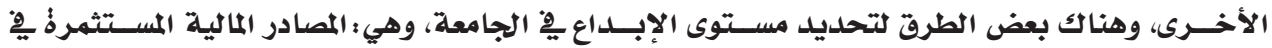

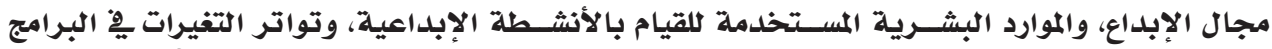

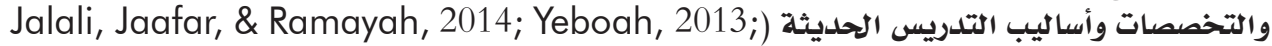

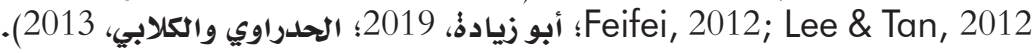

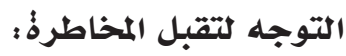

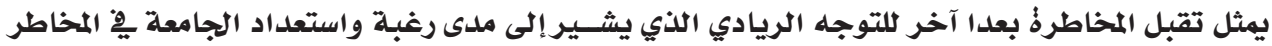

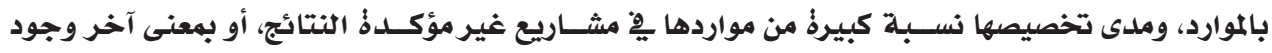

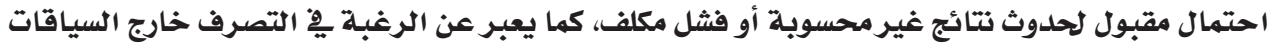




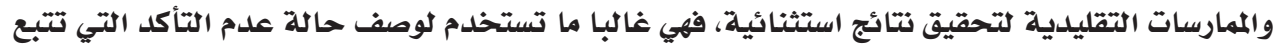

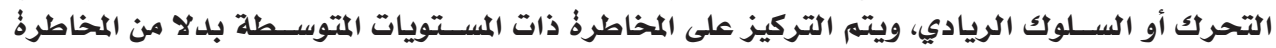

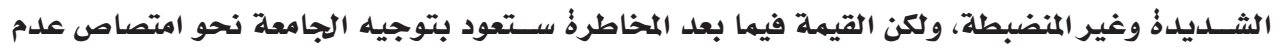

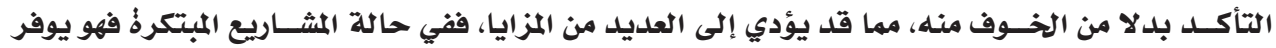

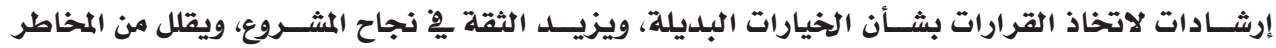

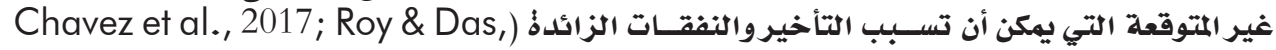
2017; Porananond \& Thawesaengskulthai, 2014; Kraus, Rigtering, Hughes, \&

.(Hosman, 2012; Pearce et al., 2010

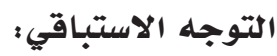

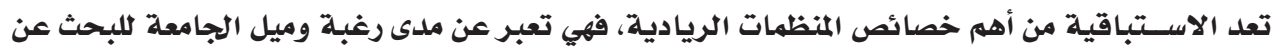

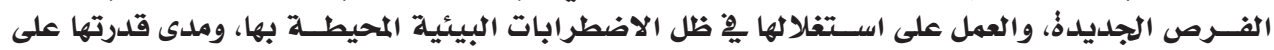

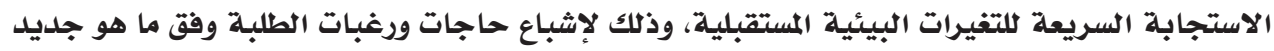

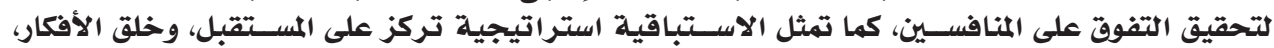

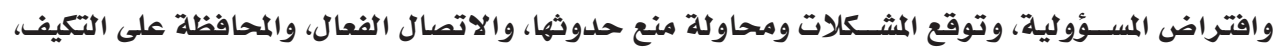

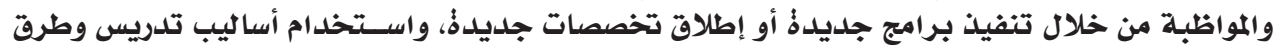

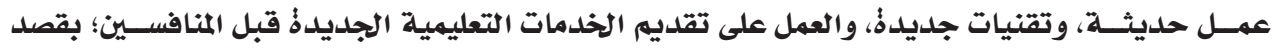

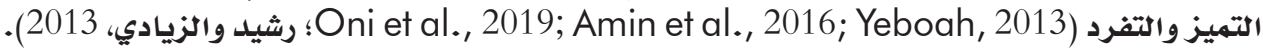

\section{مشكلة الدراسة وأسئلتها:}

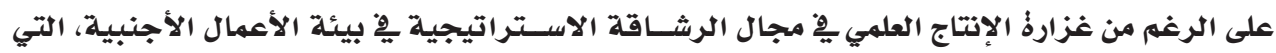

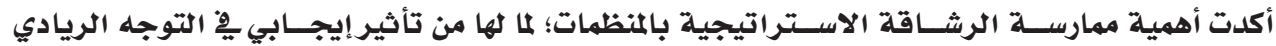
،Govender, 2020; Khorshid, 2018; Tahmasebifard et al., 2017; Ayub et al., 2014)

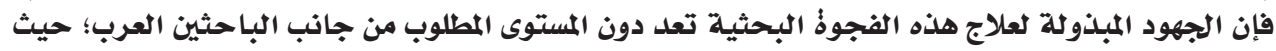

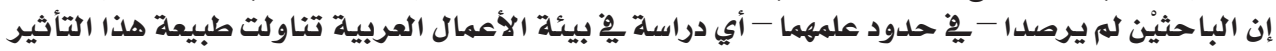

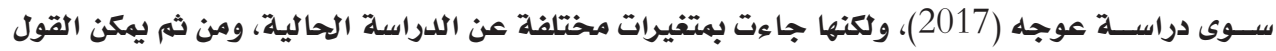

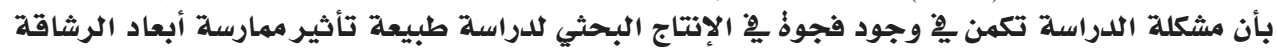

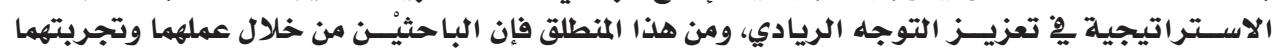

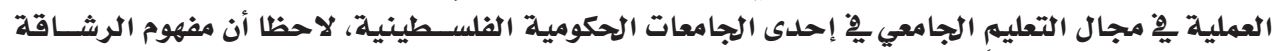

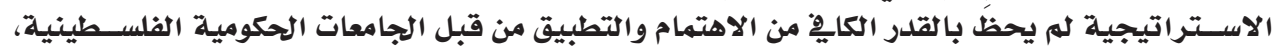

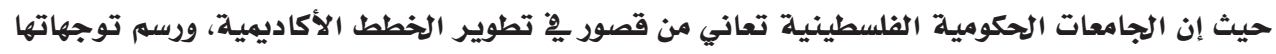

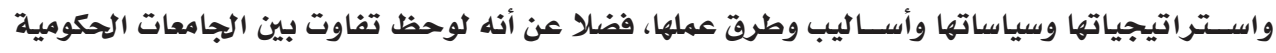

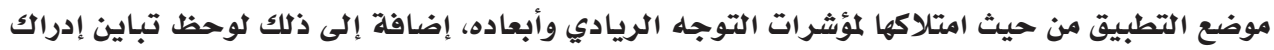

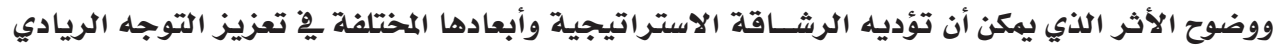

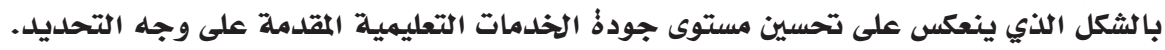

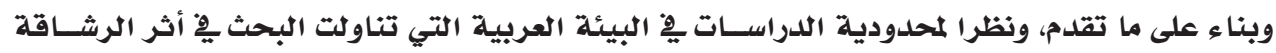

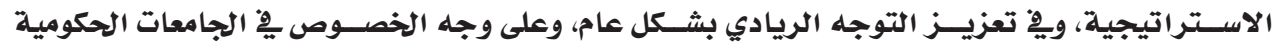

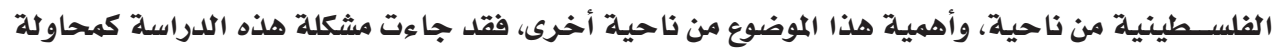

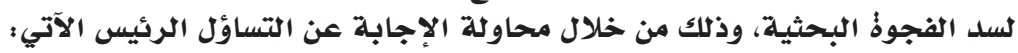

ه ما أثر الرشاقة الاستراتيجية يِّ تعزيز التوجه الريادي يِّ الجامعات الحكومية الفلسطينية، من وجهة نظر العاملين بالوظائف الإشرافية فيهاء 
زكي عبد المعطي أبو زيادةٌ إيناس موسى الزين

المجلد الرابع عشر العدد (50) 2021م إيناس موسى الزين

وينبثق عن هذا التساؤل الرئيس الأسئلة الفرعية الآتية ؛

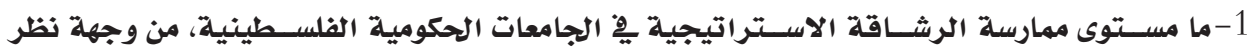

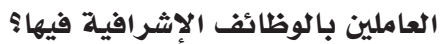

2-ما مدى تبني التوجه الريادي لدى الجامعات الوفية الحكومية الفلسطينية، من وجهة نظر العاملين بالوظائف

الإشرافية فيها؟

3-هل يوجد تأثير ذو دلالة إحصائية لممارسة أبعاد الرشاقة الاستراتيجية يِّة تعزيز التوجه الريادي

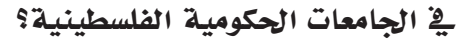

أهـداف الدراسة:

من أجل الإحاطة بأبعاد مشكلة الدراسة، تسعى هذه الدراسة إلى تحقيق الأهداف الآتية :

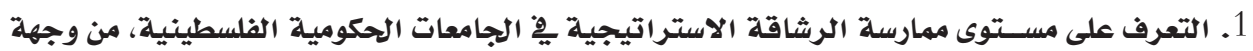

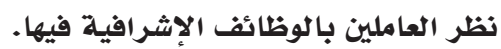

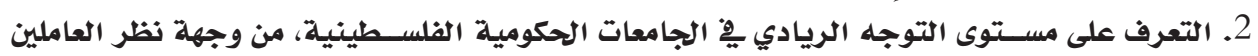

بالوظائف الإشرافية فيها.

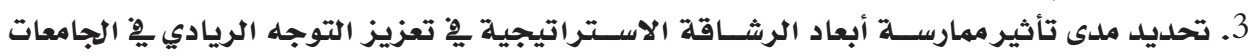

الحكومية الفلسطينية.

أهمية الدمراسة:

تستهد هذه الدراسة أهميتها من جانبين؛ هما :

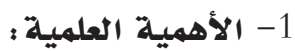

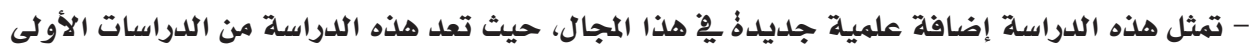

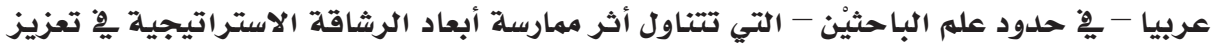

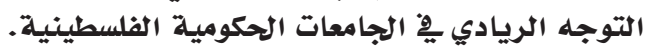

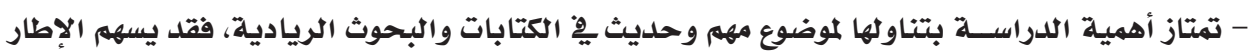

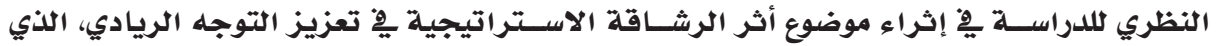

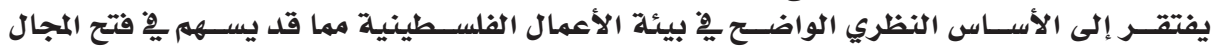

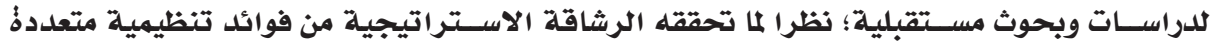

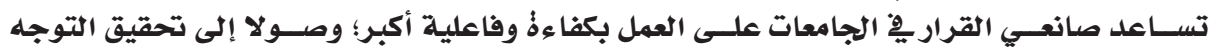
الريادي. تشابـا

2- الأهمية العملية :

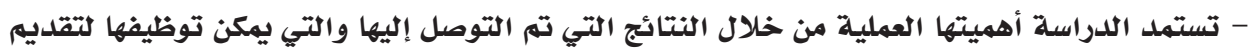

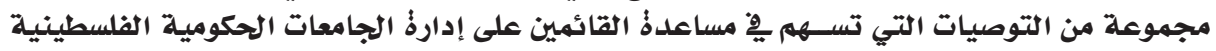

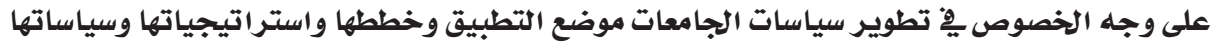

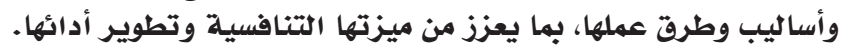
أنموذج الدراسة:

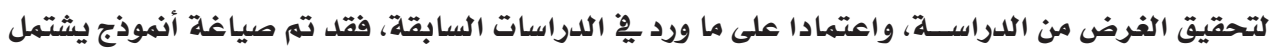
على أبعاد الرشاقة الاستراتيجية كمتفير مستقل، والتوجه الترادي الريادي كمتفير تابع. 
وفيما يلي توضيح لهذا النموذج:

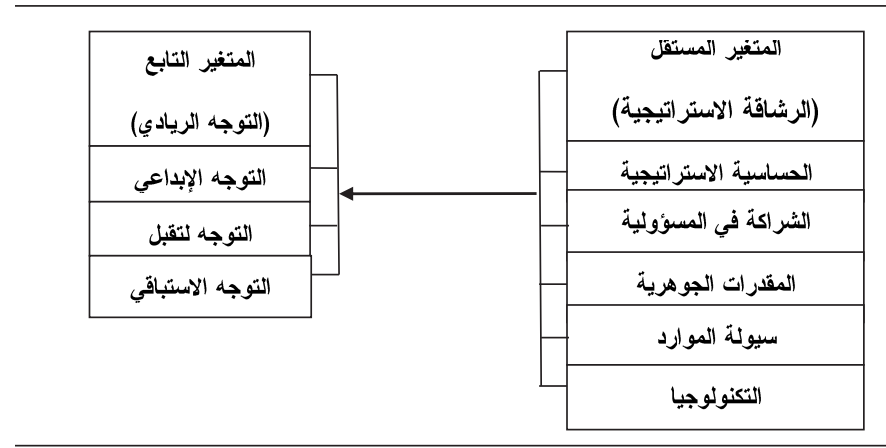

شكل (1) : أنموذج الدراسة

فرضيات الدراسة :

وِِِ ضوء ما سبق، تسعى الدراسة إلى اختبار الفرضيات الصفريـة (HO) الآتية :

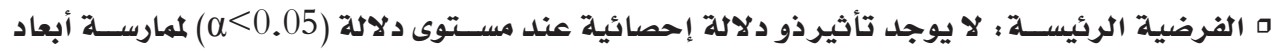

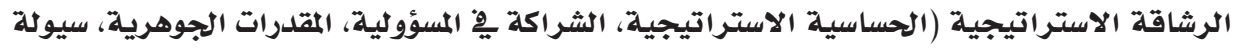

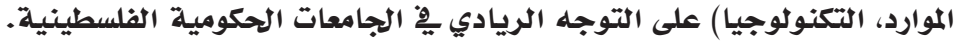

$$
\text { وينبثق عن الفرضية الرئيسة الفرضيات الفرعية الآتية ؛ }
$$

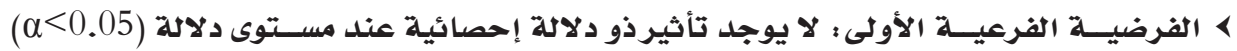

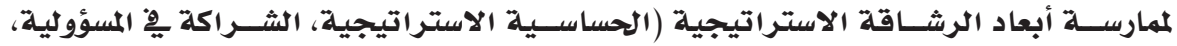

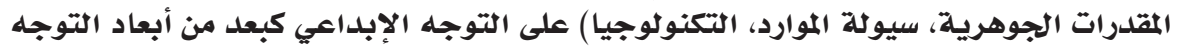

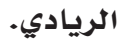

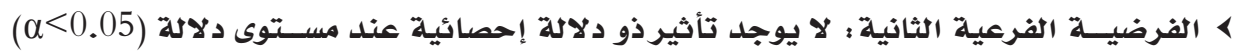

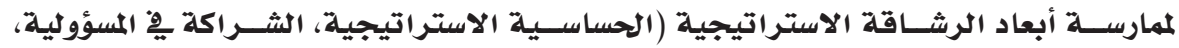

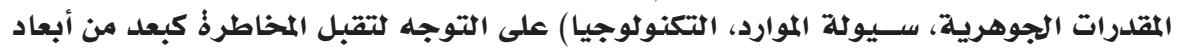

$$
\text { التوجه الريادي. }
$$

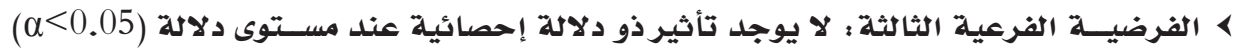

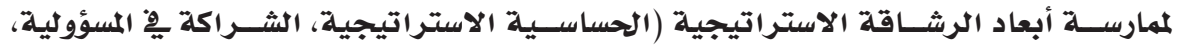

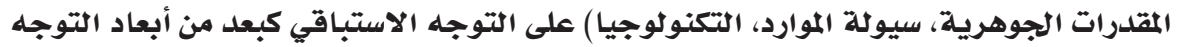

$$
\text { الريادي. }
$$

$$
\text { منهج الدراسية الدراسة وإجـراءاتها: }
$$

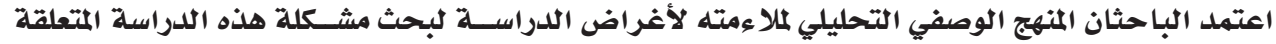

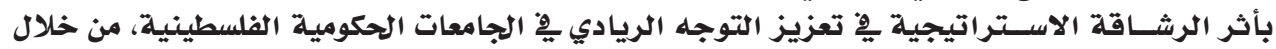

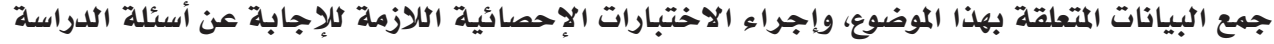

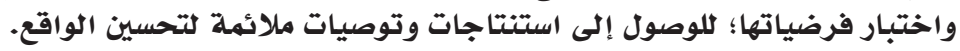


زكي عبد المعطي أبو زيادذٌ إيناس موسى الزين

المجلد الرابع عشر العدد (50) 2021م إئاسن موسى الزين

مجتمع الدراسلة وعينتها :

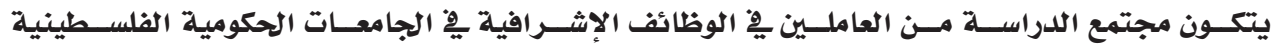

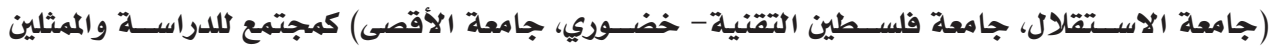

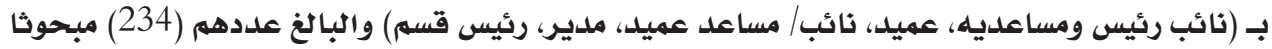

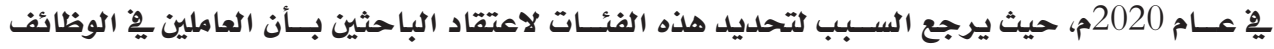

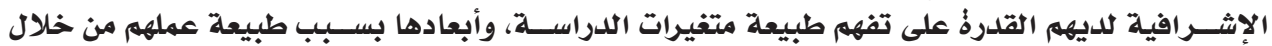

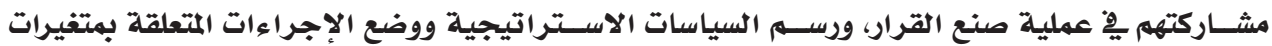

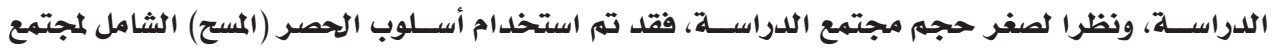

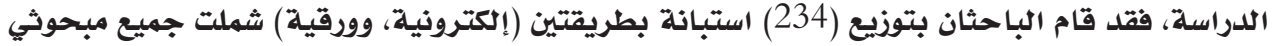

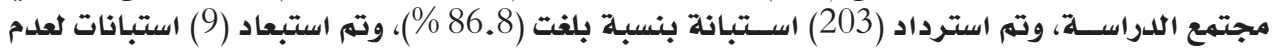

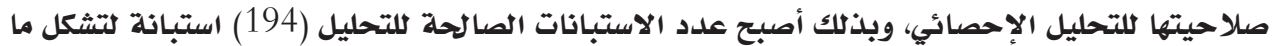

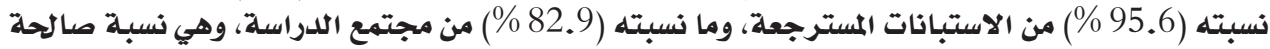
لأغراض البحث العلمي.

جدول (1): توصيف لعينة الدراسة من واقع الاستبانات الصالحة للتحليل

\begin{tabular}{|c|c|c|c|}
\hline \multirow{2}{*}{ النسبة المئوية } & \multirow{2}{*}{ التكرار } & \multicolumn{2}{|c|}{ المتغيرات الشخصية والوظيفية } \\
\hline & & ذكر & الجنس \\
\hline$\% 11.9$ & 23 & 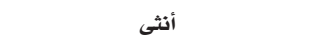 & \\
\hline$\% 18.0$ & 35 & أقل من 35 سنة & العمر \\
\hline$\% 43.8$ & 85 & من 35 إلى أقل من 50 سنة & \\
\hline$\% 38.1$ & 74 & 50 سنة فأكثر & \\
\hline$\% 3.1$ & 6 & أقل من 10سنوات & عدد سنوات الخبرة: \\
\hline$\% 21.6$ & 42 & من 10إلى أقل من 15سنة & \\
\hline$\% 24.7$ & 48 & من 15إلى أقل من 20 سنة & \\
\hline$\% 50.5$ & 98 & 20 سنة فأكثر & \\
\hline$\% 17.0$ & 33 & بكالوريوس & المؤهل العلمي \\
\hline$\% 25.8$ & 50 & ماجستير & \\
\hline$\% 57.2$ & 111 & 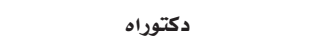 & \\
\hline$\% 8.2$ & 16 & نائب رئيس ومساعديه & المسمى الوظيفي \\
\hline$\% 14.9$ & 29 & عميد & \\
\hline$\% 8.8$ & 17 & نائب/ مساعد عميد & \\
\hline$\% 26.3$ & 51 & 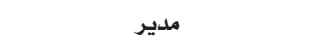 & \\
\hline$\% 41.8$ & 81 & رئيس قسم & \\
\hline$\% 19.5$ & 38 & الاستقلال & ال الجامعة \\
\hline$\% 31.3$ & 61 & جامعة فلسطين التقنية (خضوري) & \\
\hline$\% 48.7$ & 95 & الاقصى & \\
\hline
\end{tabular}

أداةٌ الدراسلة :

ولتحقيق أهداف الدراسة وللحصول على المعلومات والبيانات استخلدمت الدراسة مصدرين رئيسيين، وهما :

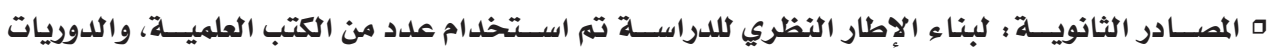

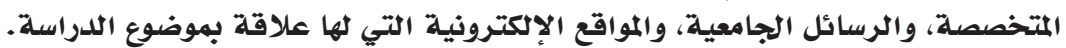

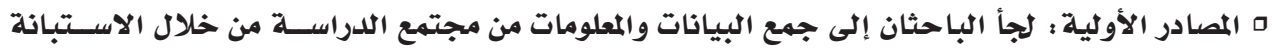

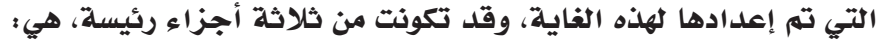


< الجزء الأول : يتكون من البيانات الشـخصية والوظيفية لمجتمع الدراســة : (الجنس، العمر، سنوات

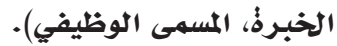

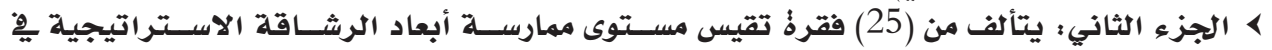

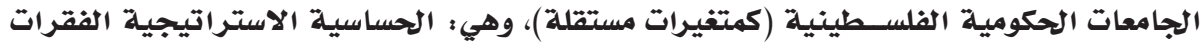

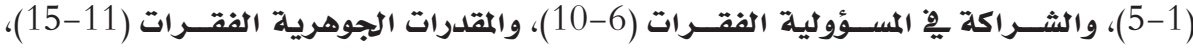

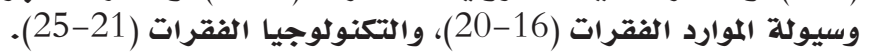

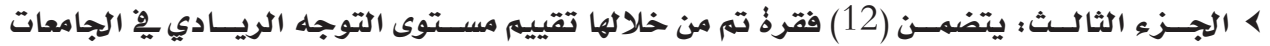

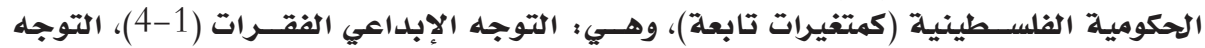

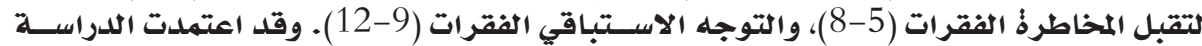

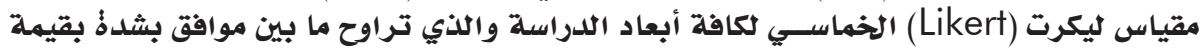

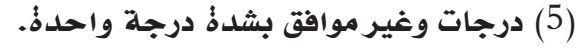

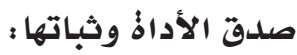

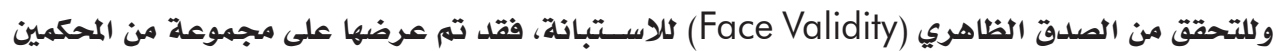

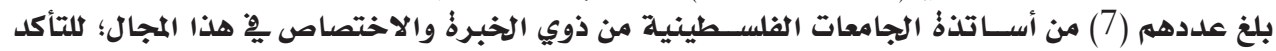

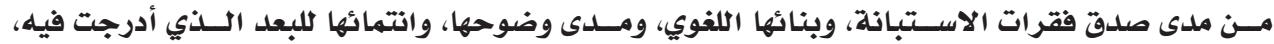

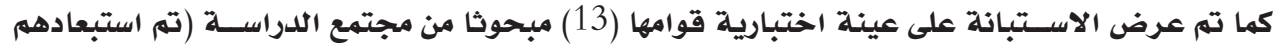

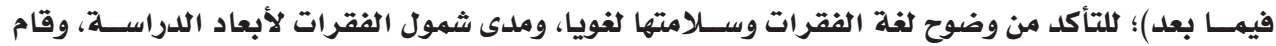

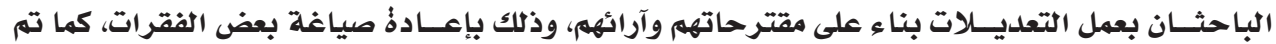

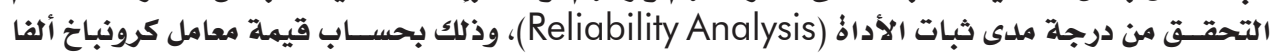
(Cronbachs' Alpha) جدول (2): قيمة معامل كرونباخ ألفا لمتغيرات الدراسة

\begin{tabular}{|c|c|}
\hline قيمة ألفا & المتغيرات \\
\hline$\% 93.4$ & المتغير المستقل (أبعاد الرشاقة الاستراتيجية). \\
\hline$\% 88.6$ & المتغير التابع (التوجه الريادي). \\
\hline$\% 94.8$ & كافة المتغيرات (الأداذُ ككل) مجتمعة. \\
\hline
\end{tabular}

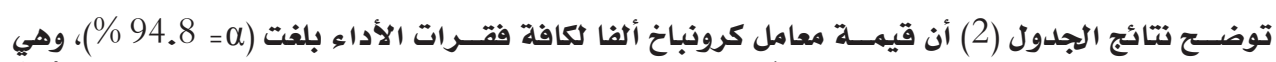

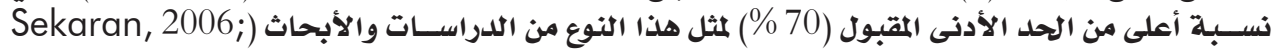
بورة (Hair, Anderson, Tatham, \& Black, 2006 بصورة عامة على درجة ثبات عالية ومقبولة لأغراض إجراء الدراسة، وبالتالي إمكانية تعميم نتائجها على مجتمع الدراسلة.

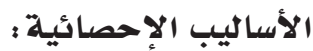

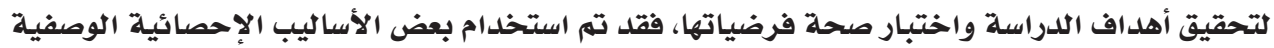

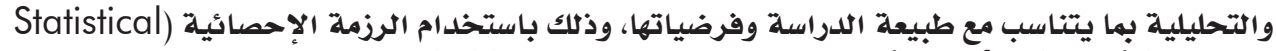
Package for Social Sciences

\section{نتائج الدراسة ومناقشت أنتها:}

أولا : النتائج المتعلقة بتحليل أسئلة الدراسلة ومناقشتها:

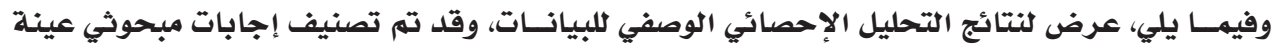

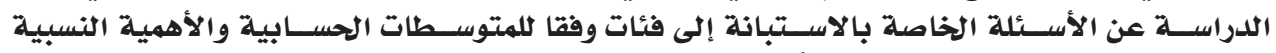

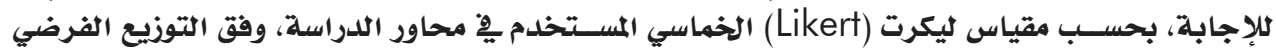

الآتي، أنظر الجدول (3) : 


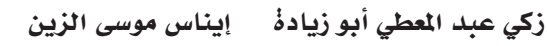

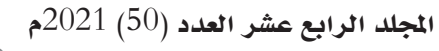

جلدول (3) : درجات أو مستويات قياس النتائج الوصفية

\begin{tabular}{|c|c|c|c|c|c|}
\hline منخفضة جدا & منخفضة & متوسطة & عالية & عالية جدا & درجة الموافقة \\
\hline \multirow[t]{2}{*}{1 أقل من 1.80} & 1.80 - أقل من & 2.60 - أقل من & 3.40 - أقل من & $5-4.20$ & الوسط الحسابي \\
\hline & 2.60 & 3.40 & 4.20 & & \\
\hline 20 \% إلى أقل من & من 36 \% إلى أقل & من 52 \% إلى أقل & من 68 \% إلى أقل & من 84 \% وحتى & الأهمية النسبية \\
\hline$\% 36$ & من 52 \% & من 68 \% & من 84 \% & $\% 100$ & \\
\hline
\end{tabular}

الســؤال الأول : ما مستوى ممارسة الرشاقة الاستراتيجية يِّ الجامعات الحكومية الفلسطينية، من وجهة نظر العاملين بالوظائف الإثرافيتو مافية فيهاء

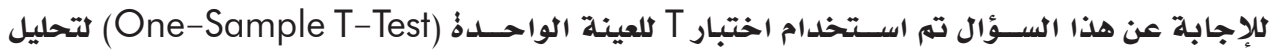

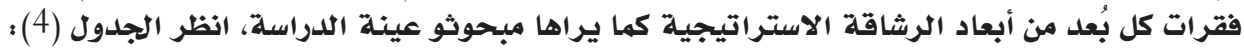

جدول (4): تحليل ممارسة أبعاد الرشاقة الاستراتيجية

\begin{tabular}{|c|c|c|c|c|c|c|c|c|}
\hline الموافقة & الأهمية حسب الترتيب & مستوى الدلاكة & اختبمة & الاهتمام & الانحراف & الحتوسط الحسب & أبعاد الرشاقة & م \\
\hline 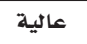 & 2 & 0.000 & $* 30.29$ & $\% 77.4$ & 0.393 & 3.87 & الحساسية الاستراتيجية & -1 \\
\hline عالية & 5 & 0.000 & $* 8.76$ & $\% 69.4$ & 0.728 & 3.47 & الشراكة ِِ المسؤولية & -2 \\
\hline عالية & 4 & 0.000 & $* 12.69$ & $\% 71.8$ & 0.631 & 3.59 & المقدرات الجوهرية & -3 \\
\hline 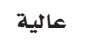 & 3 & 0.000 & $* 15.29$ & $\% 73$ & 0.583 & 3.65 & سيولة الموارد & -4 \\
\hline 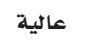 & 1 & 0.000 & $* 17.38$ & $\% 79.6$ & 0.772 & 3.98 & التكنولوجيا & -5 \\
\hline عالية ل & - & 0.000 & $* 19.63$ & $\% 74.2$ & 0.495 & 3.71 & أبعاد الرشاقة الاستراتيجية & كافة \\
\hline
\end{tabular}

ذات دلالة إحصائية عند مستوى دلالة ( 0.01 ( 0.0

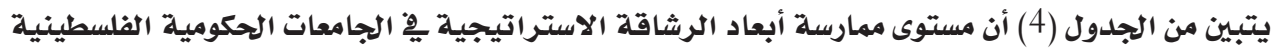

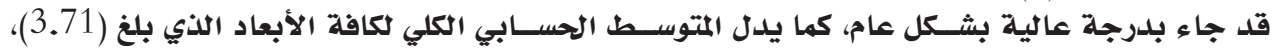

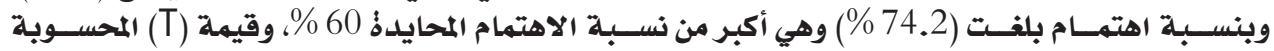

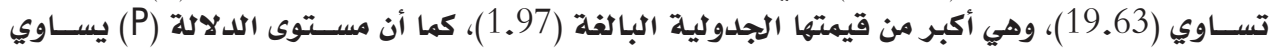

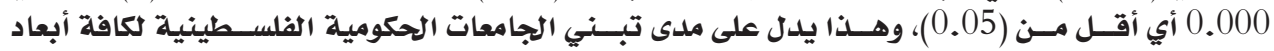

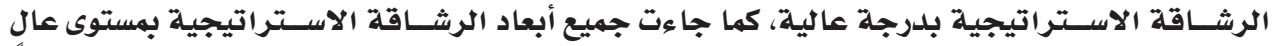

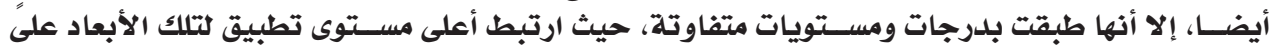

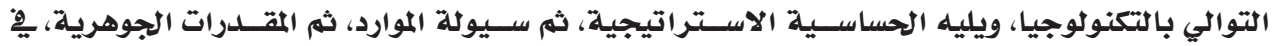

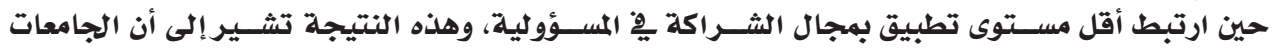

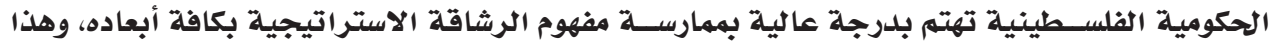

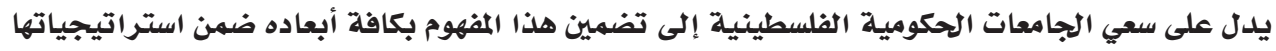

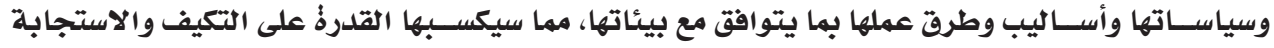

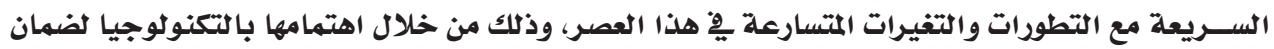

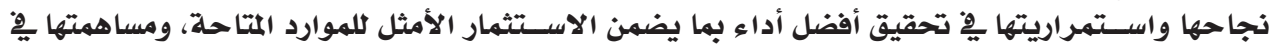

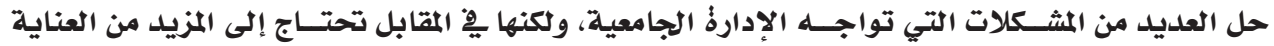

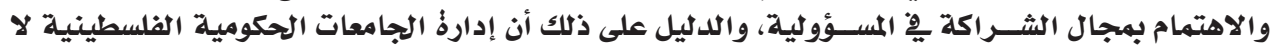

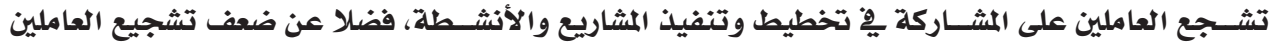

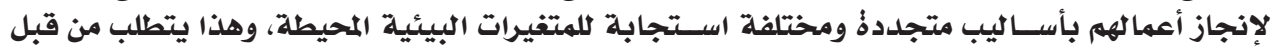




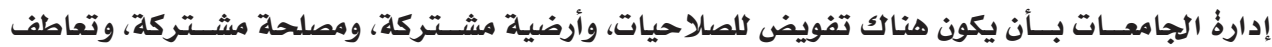

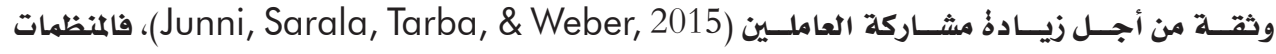

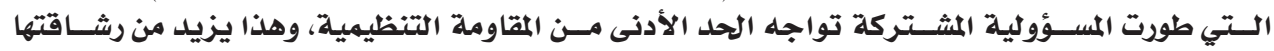
(lvory \& Brook, 2018)

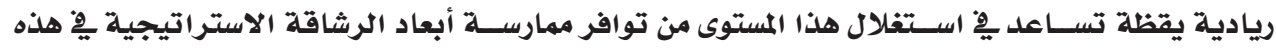

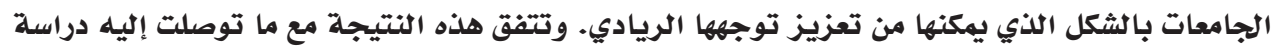

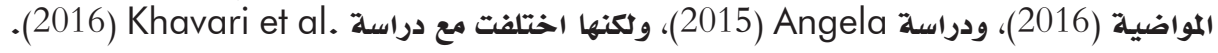

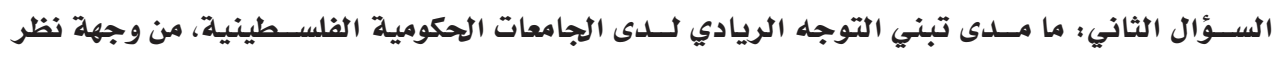

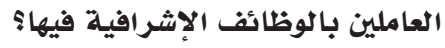

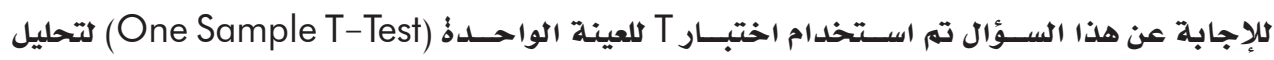

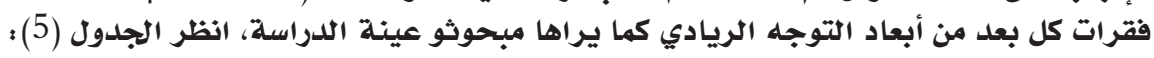
جدول (5) : تحليل الأبعاد المتعلقة بالتوجه الريادي

\begin{tabular}{|c|c|c|c|c|c|c|c|c|}
\hline الموافقة & الأهميبة حسبي & $\begin{array}{c}\text { مستوى } \\
\text { الدلاكلة } \\
(P)\end{array}$ & 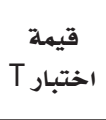 & الاهتمام & الانحراف & المستوسط ابلي & أبعاد التوجه الريادي & $\hat{r}$ \\
\hline عالية & 1 & 0.000 & 14.54 & $\% 77.6$ & 0.829 & 3.88 & التوجه الإبداعي & -1 \\
\hline 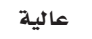 & 2 & 0.000 & 12.56 & $\% 74.2$ & 0.777 & 3.71 & التوجه لتقبل المخاطرة: & -2 \\
\hline عالية & 3 & 0.000 & 9.56 & $\% 73$ & 0.925 & 3.65 & التوجه الاستباقي & -3 \\
\hline عالية & - & 0.000 & 15.62 & $\% 75$ & 0.654 & 3.75 & كافة أبعاد التوجه الريادي & \\
\hline
\end{tabular}

* ذات دلالة إحصائية عند مستوى دلالة (0.01) 0.01 ).

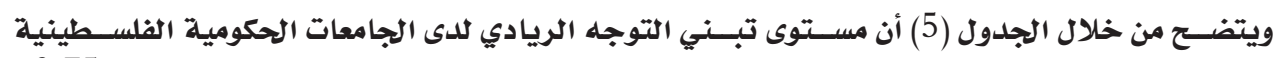

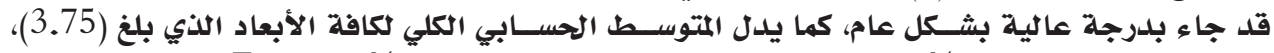

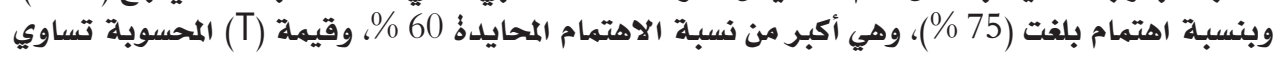

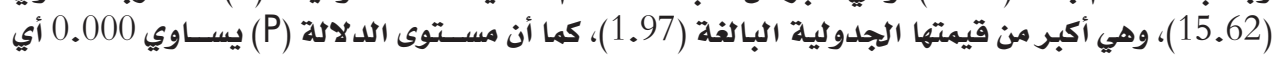

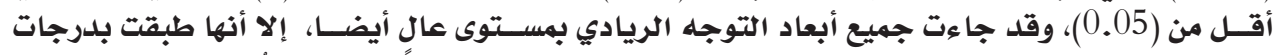

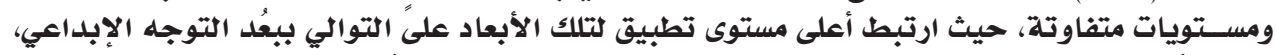

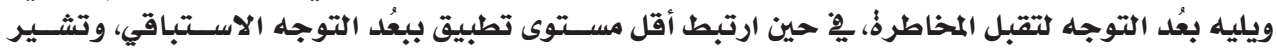

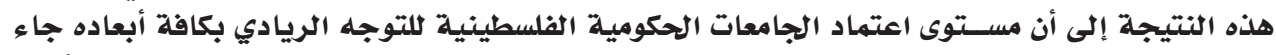

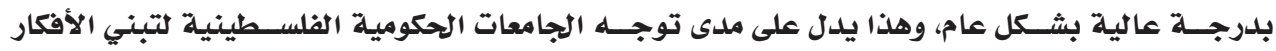

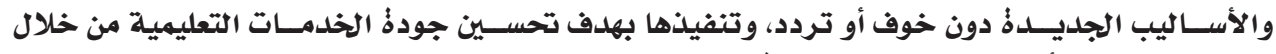

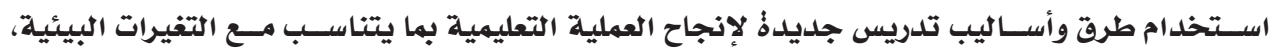

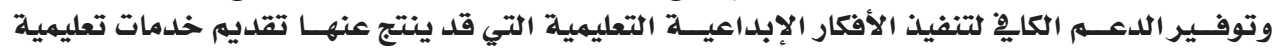

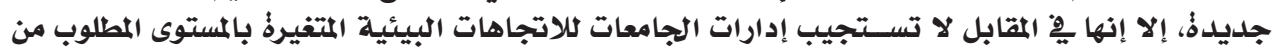

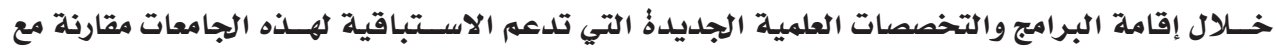

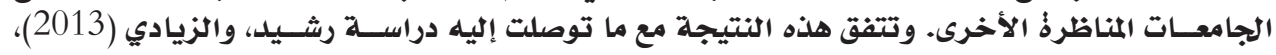

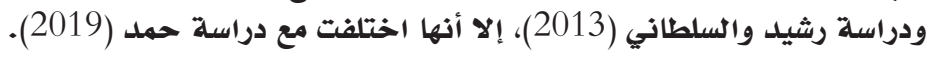
ثانيا : النتائج المتعلقة باختبار فرضيات الدراسة : واسلة

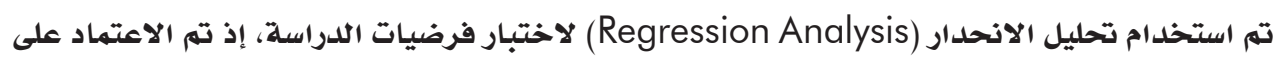

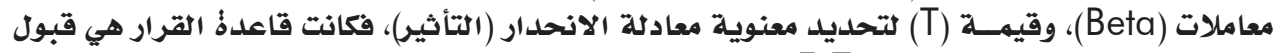

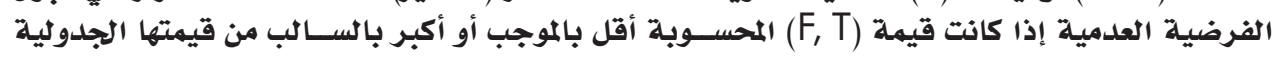




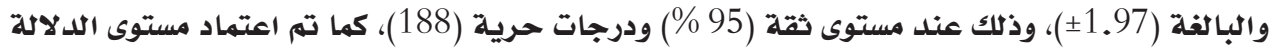

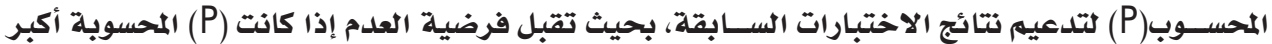

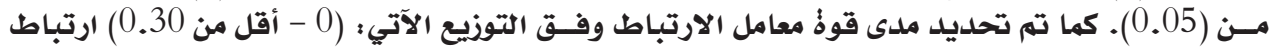

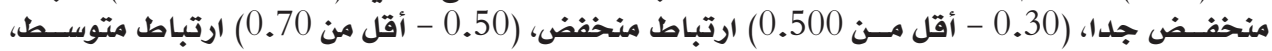

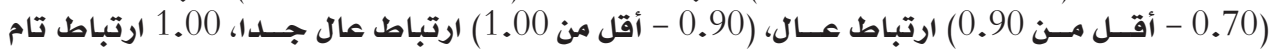
.(Hinkle, Wiersma, \& Jurs, 2003)

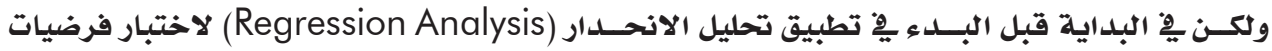

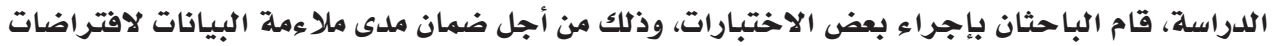

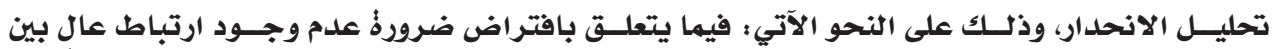

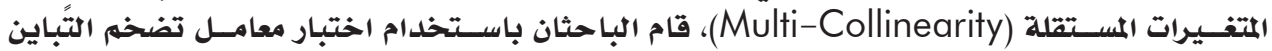
(Variance Inflation Factor) (VIF)

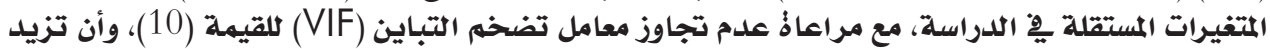

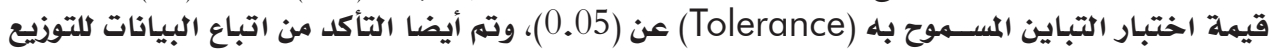

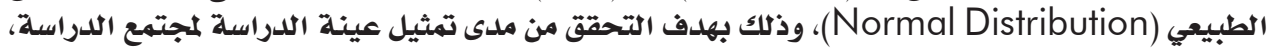

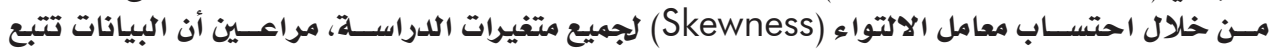

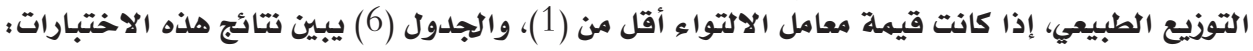

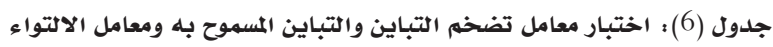

\begin{tabular}{|c|c|c|c|}
\hline معامل الالتواء (Skewness) & التباين المسموح به (Tolerance) & معامل تضخم التباين VIF & المتغيرات المستقلة \\
\hline 0.286 & 0.511 & 1.957 & الحساسية الاستراتيجية \\
\hline 0.464 & 0.311 & 3.216 & الشراكة هِّ الكسؤولية \\
\hline 0.654 & 0.275 & 3.630 & المقدرات الجوهرية \\
\hline 0.859 & 0.402 & 2.485 & سيولة الموارد \\
\hline 0.713 & 0.371 & 2.697 & التكنولوجيا \\
\hline
\end{tabular}

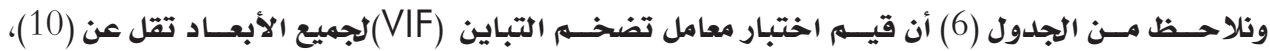

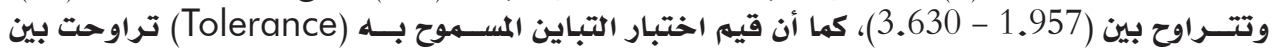

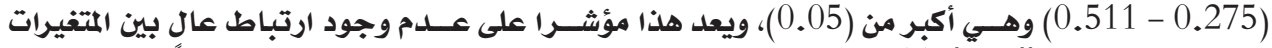

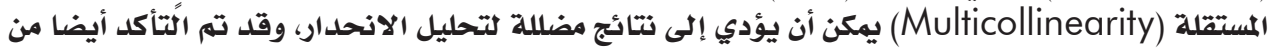

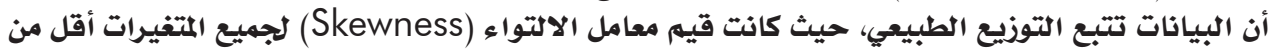

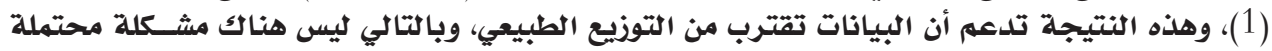

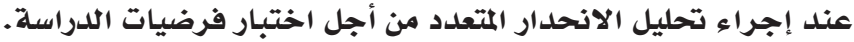

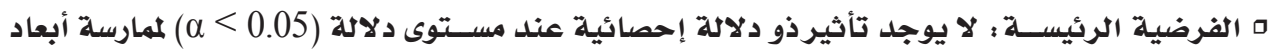

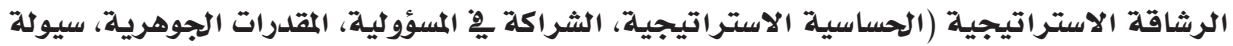

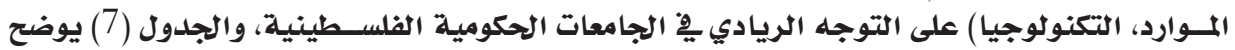
نتائج هذه الفرضية. 
جلدول (7) : نتائج تحليل الانحدار المتعدد (Multiple Regression Analysis) لاختبار تأثير ممارسة أبعاد الرشاقة الاستراتيجية على التوجه الريادي يف الجامعات الحكومية الفلسطينية

\begin{tabular}{|c|c|c|c|c|c|c|}
\hline \multirow{2}{*}{ نتيجة الفرضية } & \multirow{2}{*}{ مستوى دلاكة } & \multirow{2}{*}{ T قيمة T } & \multirow{2}{*}{$\begin{array}{c}\text { المعاملارية Beta } \\
\text { Beta }\end{array}$} & \multicolumn{2}{|c|}{ المعاملات غير المعيارية } & \multirow{2}{*}{ أبعاد الرشاقة أليجية } \\
\hline & & & & الخطأ المعياري & $B$ & \\
\hline- & 0.001 & $* 3.324$ & - & 0.355 & 1.180 & الثابت \\
\hline قبول (لا يوجد تأثير) & 0.652 & ${ }^{* *} 0.452$ & 0.028 & 0.103 & 0.046 & الحساسية الاستراتيجية \\
\hline رفض (يوجد تأثير) & 0.000 & $* 6.041$ & 0.485 & 0.071 & 0.426 & الشراكة ِِِ المسؤولية \\
\hline رفض (يوجد تأثير) & 0.004 & ${ }^{*} 2.930$ & 0.250 & 0.086 & 0.253 & المقدرات الجوهرية \\
\hline رفض (يوجد تأثير) & 0.000 & $* 4.013$ & 0.283 & 0.076 & 0.306 & سيولة الموارد \\
\hline رفض (يوجد تأثير) & 0.000 & $* 4.640$ & 0.341 & 0.061 & 0.281 & التكنولوجيا \\
\hline
\end{tabular}

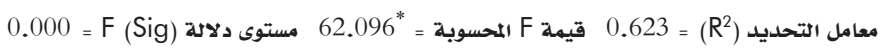

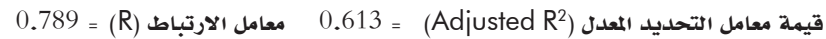

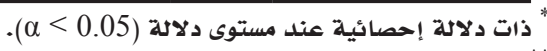

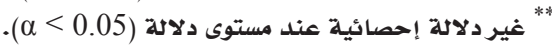

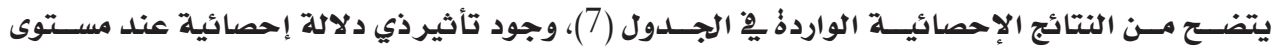

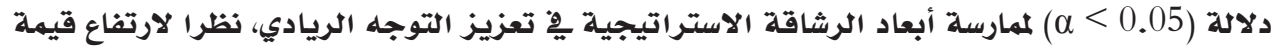

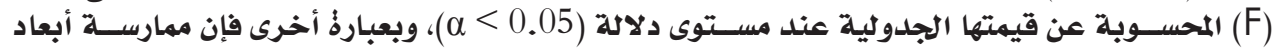

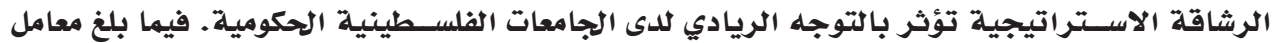

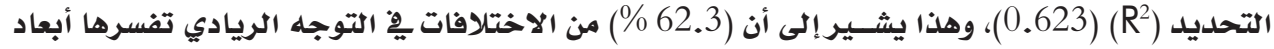

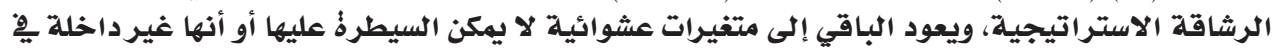

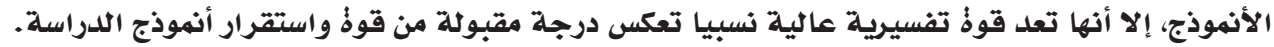

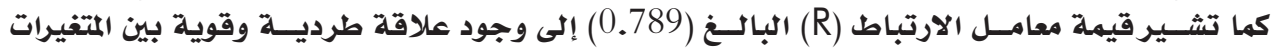

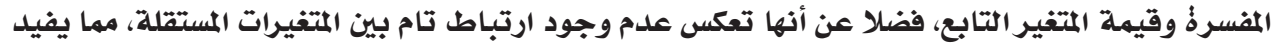

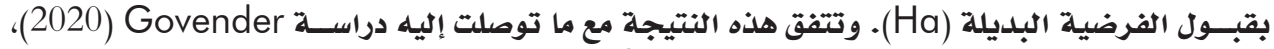

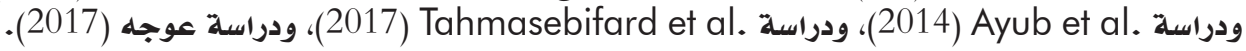

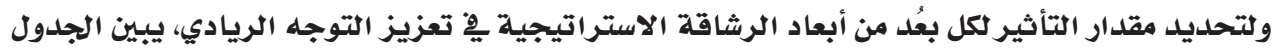

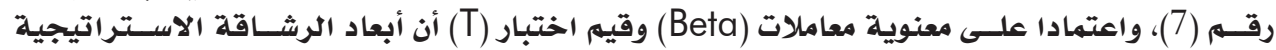

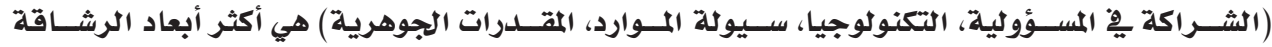

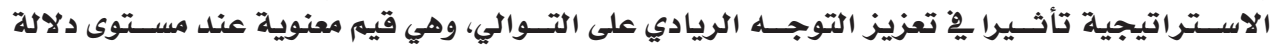

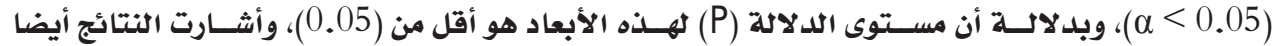

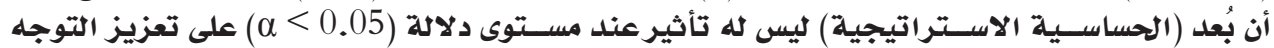

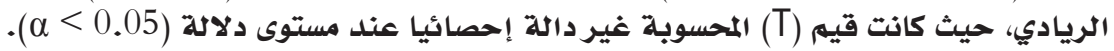

وينبثق عن الفرضية الرئيسة الفرضيات الفرعية الآتية ؛

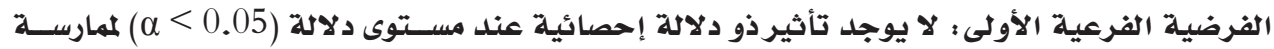

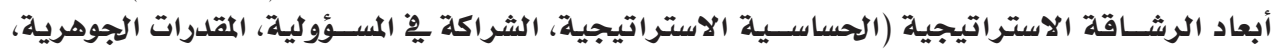

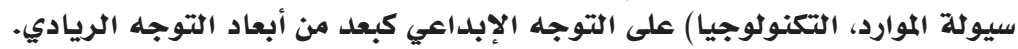




$$
\begin{aligned}
& \text { زكي عبد المعطي أبو زيادةٌ إيناس موسى الزين } \\
& \text { المجلد الرابع عشر العدد (50) 2021م إلمادئ }
\end{aligned}
$$

جلدول (8) : نتائج تحليل الانحدار المتعدد (Multiple Regression Analysis) لاختبار تأثير ممارسة أبعاد الرشاقة

\begin{tabular}{|c|c|c|c|c|c|c|}
\hline \multirow{2}{*}{ نتيجة الفرضية } & \multirow{2}{*}{ مستوى دلالة } & \multirow{2}{*}{ 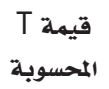 } & \multirow{2}{*}{ 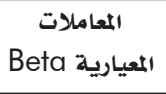 } & \multicolumn{2}{|c|}{ المعاملات غير المعيارية } & \multirow{2}{*}{ أبعاد الرشاقة } \\
\hline & & & & الخطأ المعياري & $B$ & \\
\hline- & 0.000 & $* 5.266$ & - & 0.257 & 1.355 & الثابت \\
\hline رفض (يوجد تأثير) & 0.000 & $* 4.201$ & 0.148 & 0.074 & 0.313 & الحساسية الاستراتيجية \\
\hline قبول (لا يوجد تأثير) & 0.167 & ${ }^{* *} 1.386$ & 0.063 & 0.051 & 0.071 & الشراكة بِّ المسؤولية \\
\hline رفض (يوجد تأثير) & 0.000 & $* 9.301$ & 0.446 & 0.062 & 0.581 & المقدرات الجوهرية \\
\hline رفض (يوجد تأثير) & 0.000 & $* 3.799$ & 0.151 & 0.055 & 0.320 & سيولة الموارد \\
\hline رفض (يوجد تأثير) & 0.000 & $14.073^{*}$ & 0.581 & 0.044 & 0.619 & التكنولوجيا \\
\hline
\end{tabular}
الاستراتيجية على التوجه الإبداعي كبعد من أبعاد التوجه التوله الريادي

$0.000=$ F (Sig) المحسوبة = $0.881=\left(R^{2}\right)$ معامل التحديد 278.51 مستوى دلالة

$0.939=($ adjusted R²)

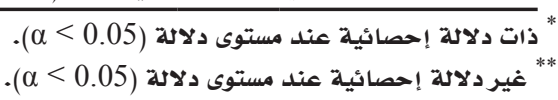

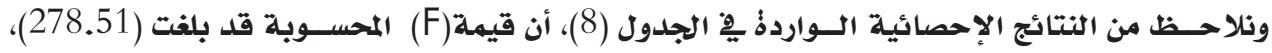

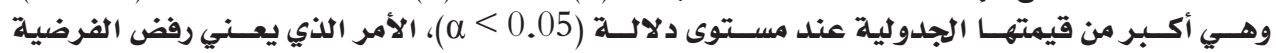

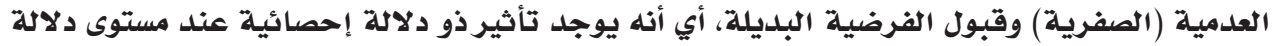

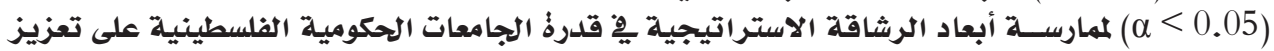

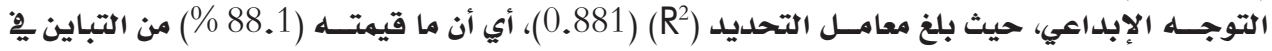

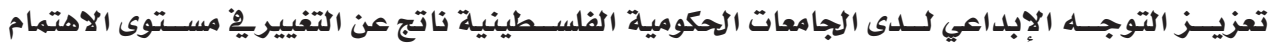

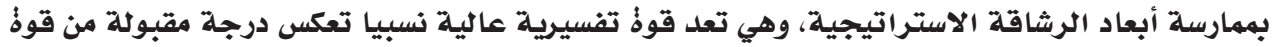

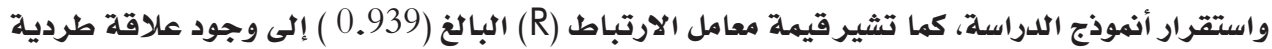

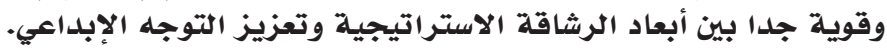

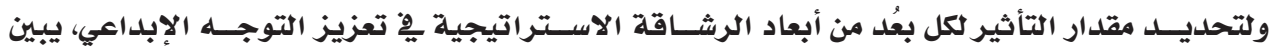

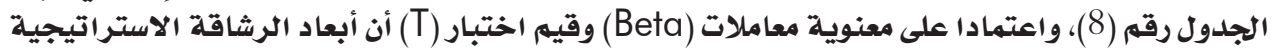

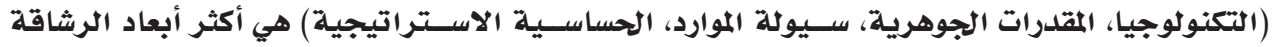

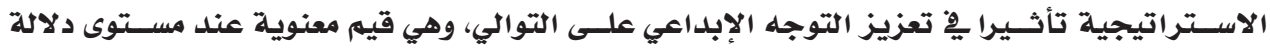

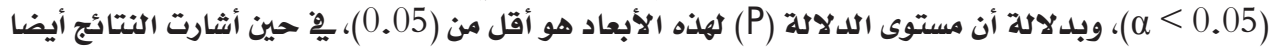

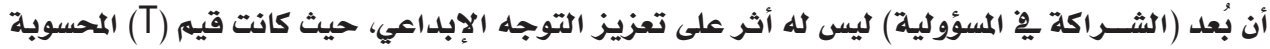

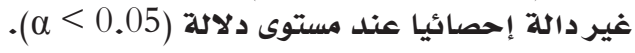

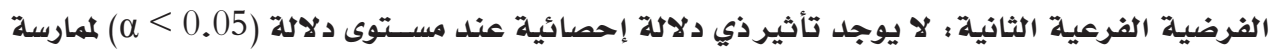

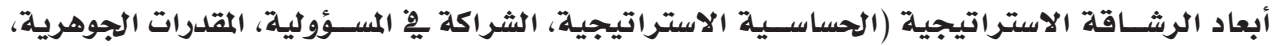

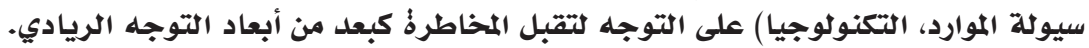

جلدول (9): نتائج تحليل الانحدار المتعدد (Multiple Regression Analysis) لاختبار تأثير ممارسة أبعاد الرشاقة

\begin{tabular}{|c|c|c|c|c|c|c|}
\hline \multirow{2}{*}{ نتيجة الفرضية (Ho) } & \multirow{2}{*}{ مستوى دلالة } & \multirow{2}{*}{ المحسوبة T } & \multirow{2}{*}{$\begin{array}{c}\text { المعيارية Beta } \\
\text { Beta }\end{array}$} & \multicolumn{2}{|c|}{ المعاملات غير المعيارية } & \multirow{2}{*}{ ألاستراد الرشيجية } \\
\hline & & & & الخطأ المعياري & $B$ & \\
\hline- & 0.240 & $* * 1.178$ & - & 0.441 & 0.520 & الثابت \\
\hline
\end{tabular}
الاستراتيجية على التوجه لتقبل المخاطرة كبعد من أبعاد التوجه الريادي 
جدول (9) : يتبع

\begin{tabular}{|c|c|c|c|c|c|c|}
\hline \multirow{2}{*}{ نتيجة الفرضية (Ho) } & \multirow{2}{*}{$\begin{array}{c}\text { مستوى دلالة } \\
\text { T (Sig) }\end{array}$} & \multirow{2}{*}{ المحسوبة Tيمة } & \multirow{2}{*}{$\begin{array}{c}\text { المعيارية المعاملات } \\
\text { Beta }\end{array}$} & \multicolumn{2}{|c|}{ المعاملات غير المعيارية } & \multirow{2}{*}{ أبعاد الرشاقة } \\
\hline & & & & الخطأ المعياري & $B$ & \\
\hline قبول (لا يوجد تأثير) & 0.516 & ${ }^{* * *} 0.651$ & 0.042 & 0.128 & 0.083 & الحساسية الاستراتيجية \\
\hline رفض (يوجد تأثير) & 0.000 & ${ }^{*} 4.822$ & 0.403 & 0.088 & 0.423 & الشراكة ِِّ الكسؤولية \\
\hline رفض (يوجد تأثير) & 0.007 & ${ }^{*} 2.712$ & 0.241 & 0.107 & 0.290 & المقدرات الجوهرية \\
\hline رفض (يوجد تأثير) & 0.001 & ${ }^{*} 3.422$ & 0.251 & 0.095 & 0.325 & سيولة الموارد \\
\hline رفض (يوجد تأثير) & 0.000 & $5.166^{*}$ & 0.395 & 0.075 & 0.389 & التكنولوجيا \\
\hline
\end{tabular}

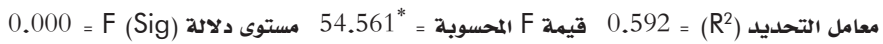

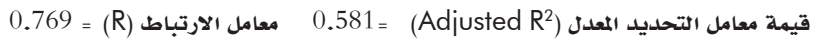

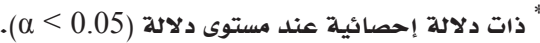

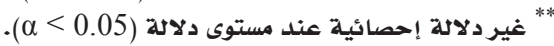

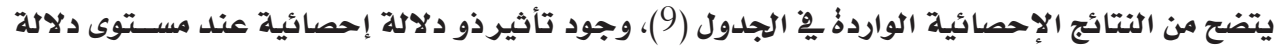

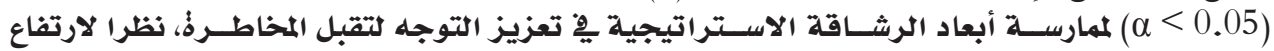

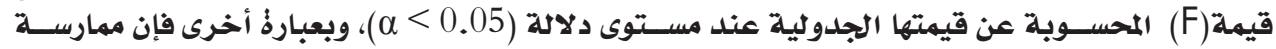

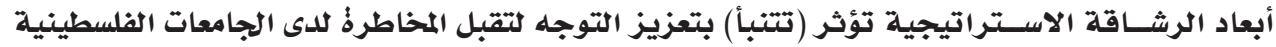

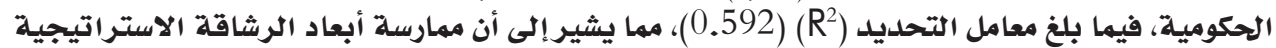

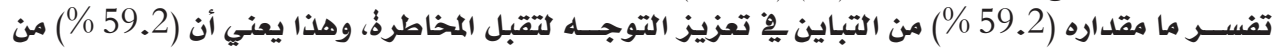

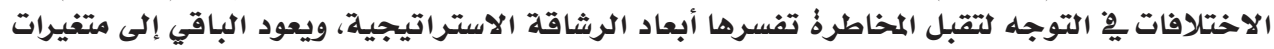

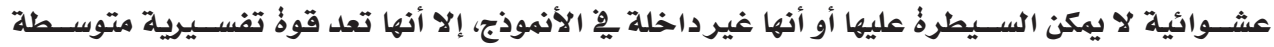

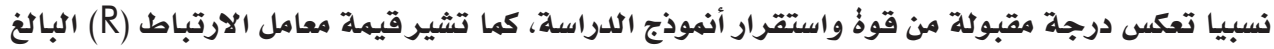

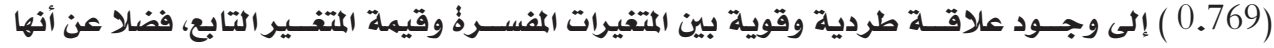

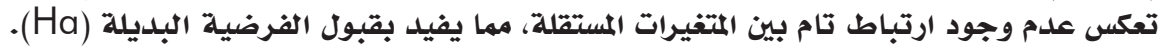

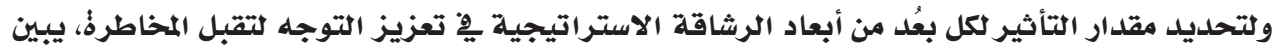

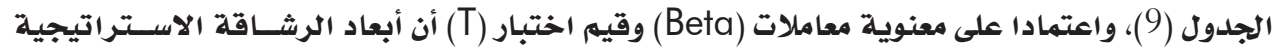

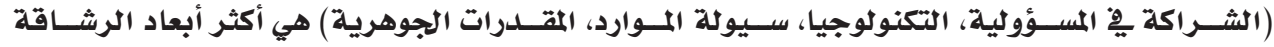

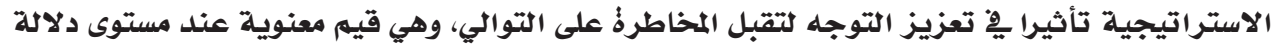

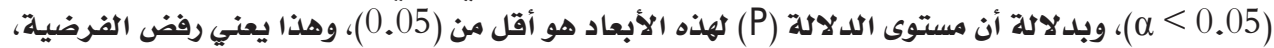

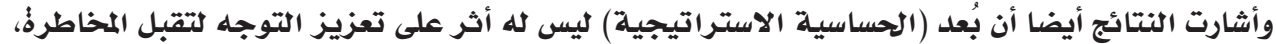

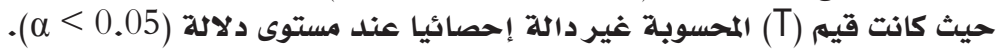

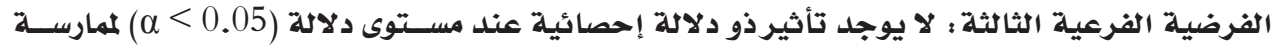

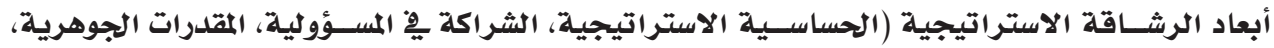

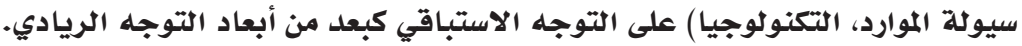

جدول (10): نتائج تحليل الانحدار المتعدد (Multiple Regression Analysis) لاختبار تأثير ممارسة أبعاد الرشاقة الاستراتيجية على التوجه الاستباقي كبعد من أبعاد التوجه الريادي لإنتاري

\begin{tabular}{|c|c|c|c|c|c|c|}
\hline \multirow{2}{*}{ نتيجة الفرضية (Ho) } & \multirow{2}{*}{$\begin{array}{c}\text { مستوى دلالة } \\
\text { T (Sig) }\end{array}$} & \multirow{2}{*}{ الميمة T ق } & \multirow{2}{*}{$\begin{array}{c}\text { المعيارية المعاملات Beta } \\
\text { Beta }\end{array}$} & \multicolumn{2}{|c|}{ المعاملات غير المعيارية } & \multirow{2}{*}{ أبعاد الرشاقة } \\
\hline & & & & الخطأ المعياري & $B$ & \\
\hline- & 0.000 & ${ }^{*} 6.189$ & & 0.707 & 4.374 & الثابت \\
\hline
\end{tabular}




$$
\begin{aligned}
& \text { زكي عبد المعطي أبو زيادةٌ إيناس موسى الزين } \\
& \text { المجلد الرابع عشر العدد (50) 2021م إئاسن موسى الزين }
\end{aligned}
$$

\begin{tabular}{|c|c|c|c|c|c|c|}
\hline \multirow{3}{*}{ نتيجة الفرضية العدمية (Ho) } & \multicolumn{5}{|c|}{ جدول (10): يتبع } & \multirow{3}{*}{ أبعاد الرشاقة البتية } \\
\hline & \multirow{2}{*}{ مستوى دلاكلة } & \multirow{2}{*}{ قلميمة T } & \multirow{2}{*}{ 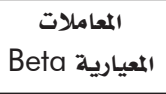 } & \multicolumn{2}{|c|}{ المعاملات غير المعيارية } & \\
\hline & & & & الخطأ المعياري & $B$ & \\
\hline قبول (لا يوجد تأثير) & 0.211 & $* * 1.255$ & 0.112 & 0.205 & 0.257 & الحساسية الاستراتيجية \\
\hline رفض (يوجد تأثير) & 0.000 & *5.587 & 0.642 & 0.141 & 0.786 & الشراكة ِِ المسؤولية \\
\hline قبول (لا يوجد تأثير) & 0.507 & ${ }^{* *} 0.664$ & 0.081 & 0.172 & 0.114 & المقدرات الجوهرية \\
\hline رفض (يوجد تأثير) & 0.012 & $* 2.526$ & 0.255 & 0.152 & 0.384 & 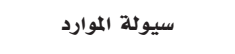 \\
\hline قبول (لا يوجد تأثير) & 0.177 & $* * 1.356$ & 0.143 & 0.121 & 0.164 & التكنولوجيا \\
\hline
\end{tabular}

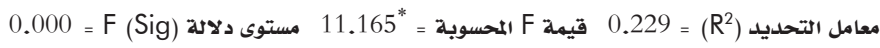

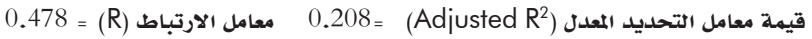

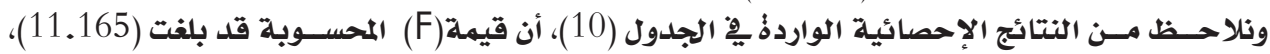

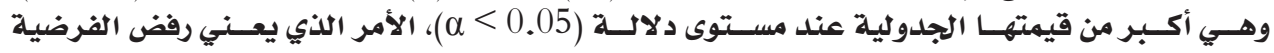

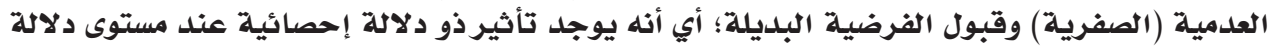

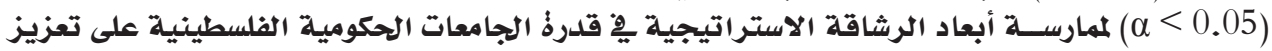

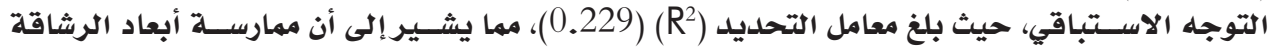

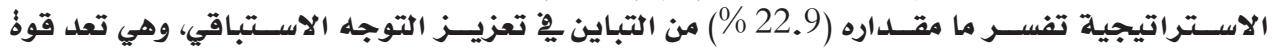

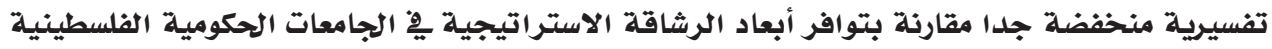

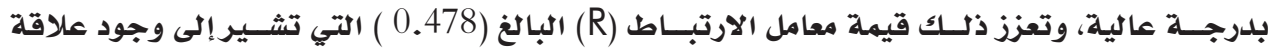

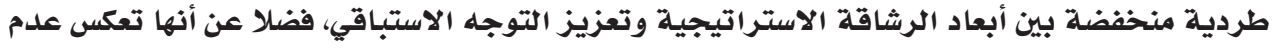

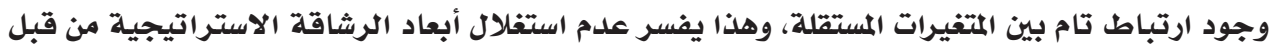

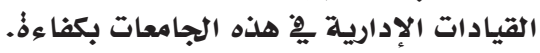

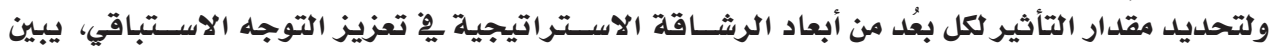

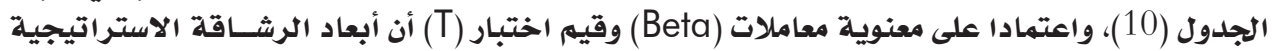

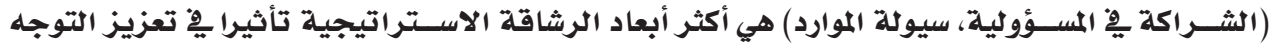

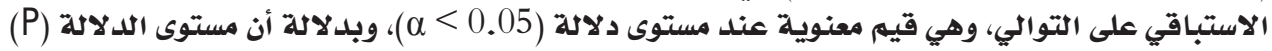

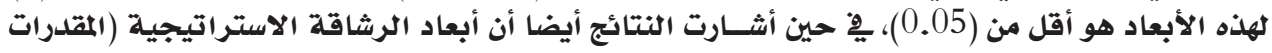

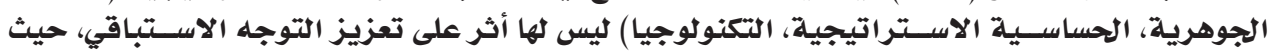

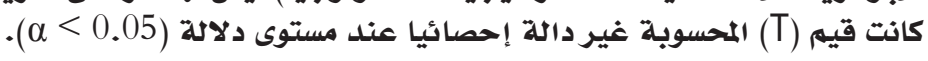

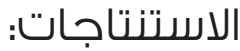

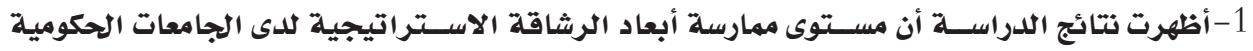

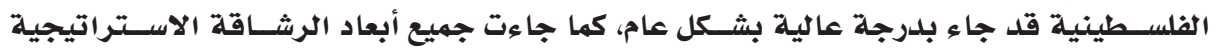

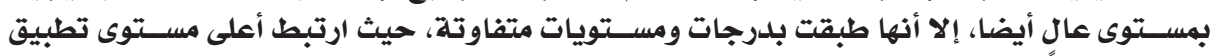

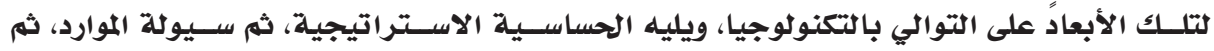

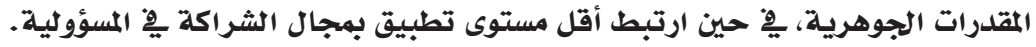

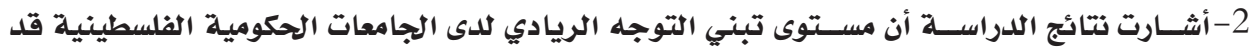

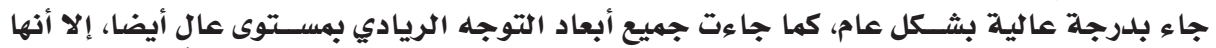

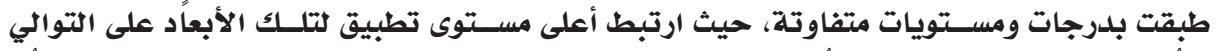

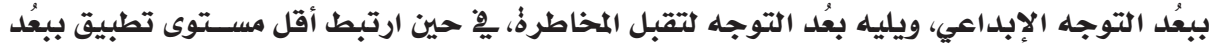
التوجه الاستباقي. 


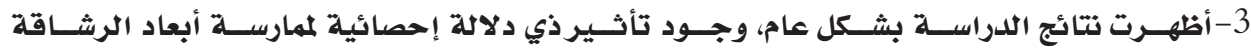

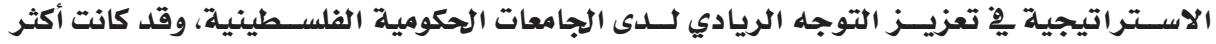

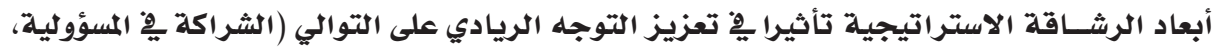

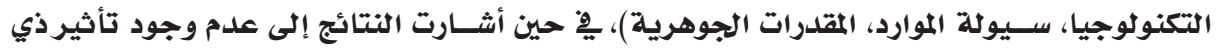

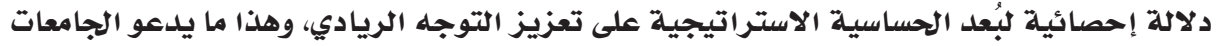

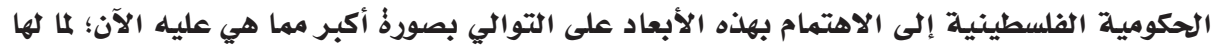

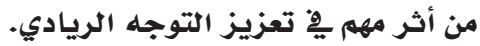

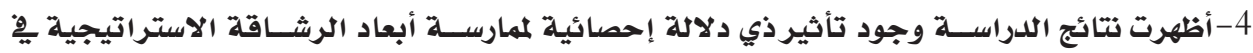

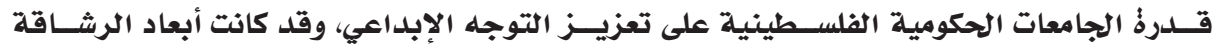

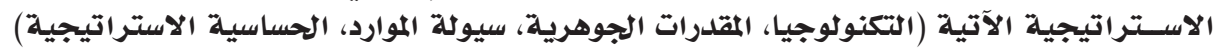

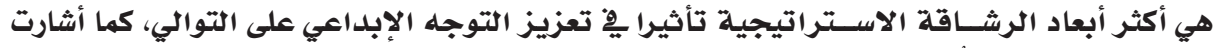

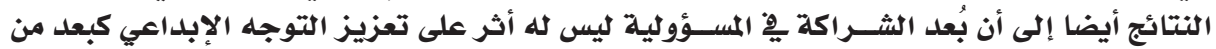
أبعاد التوجه الريادي.

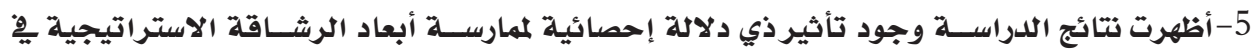

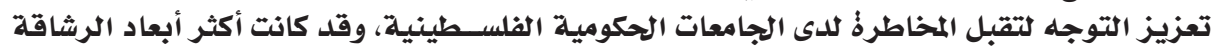

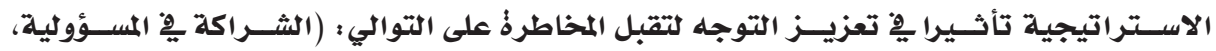

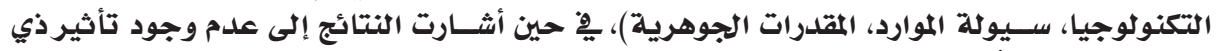

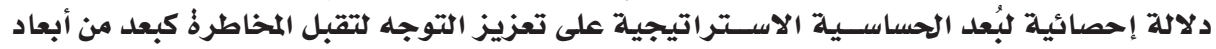
التوجه الريادي.

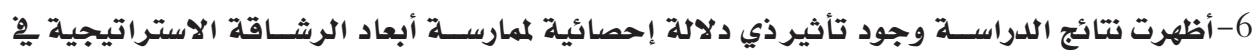

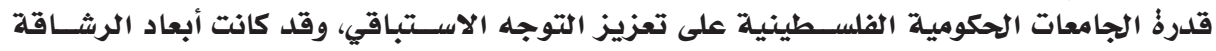

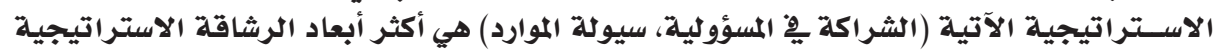

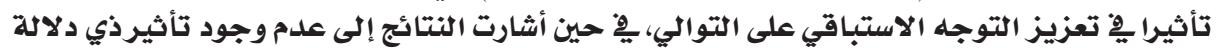

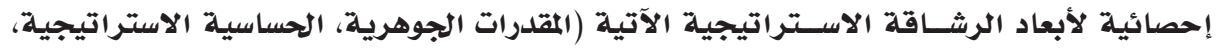

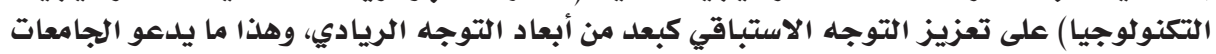

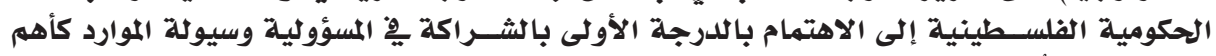

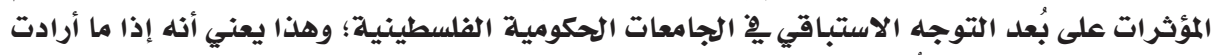

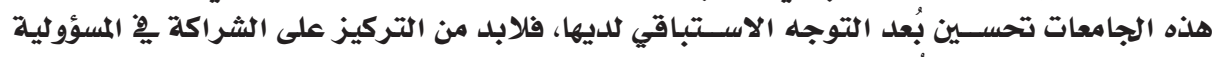

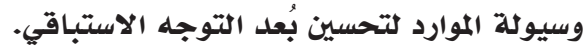

التوصيات:

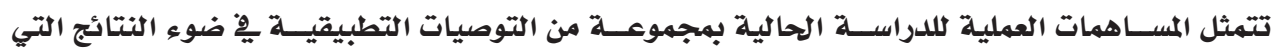

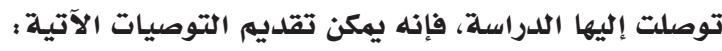

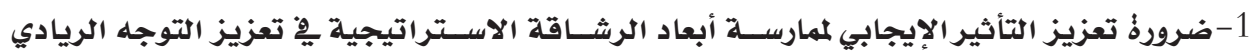

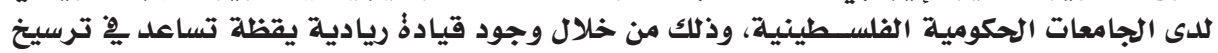

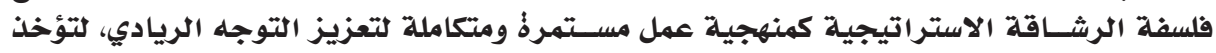

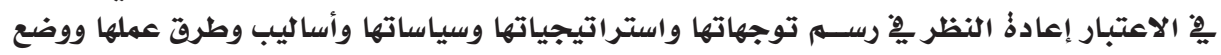

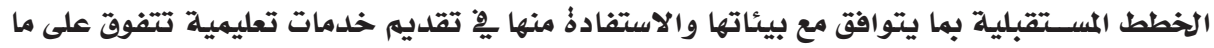

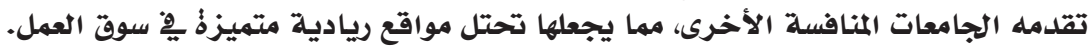

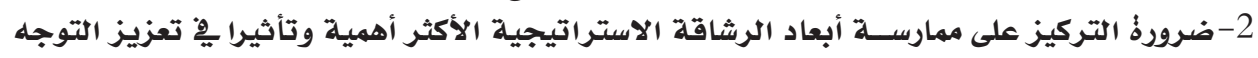

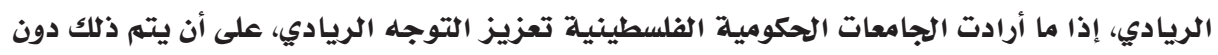


زكي عبد المعطي أبو زيادةٌ إيناس موسى الزين

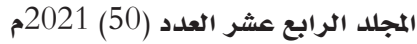

$\dot{0}$

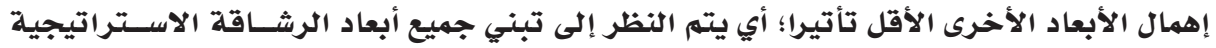

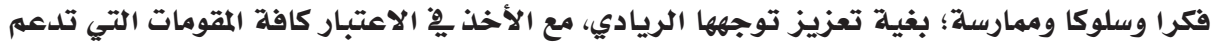

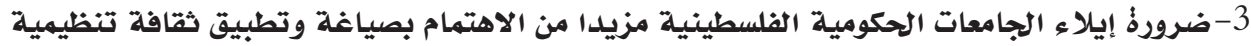

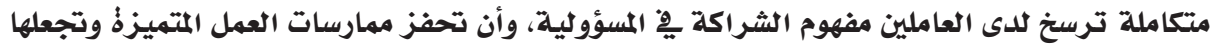

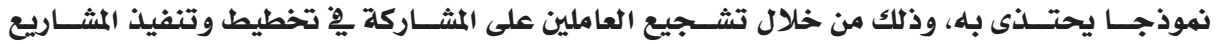

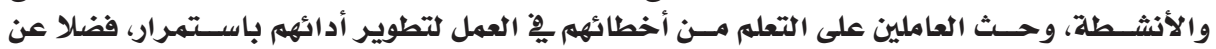

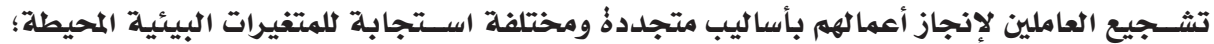

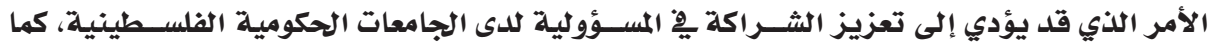
بينت نتائج الدراسية.

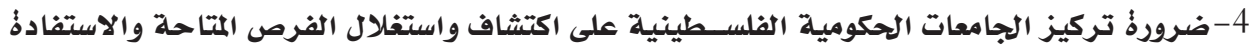

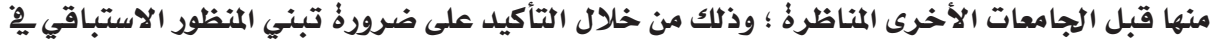

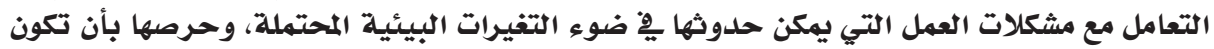

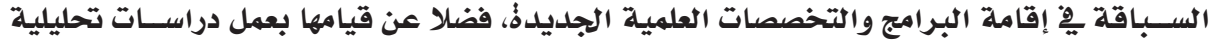

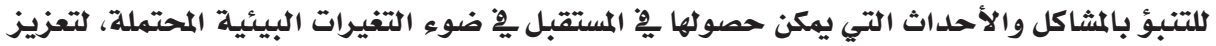

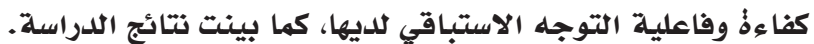

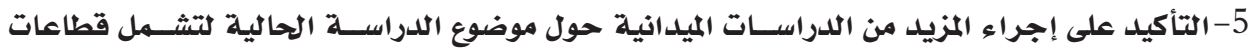

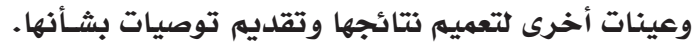

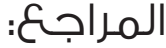

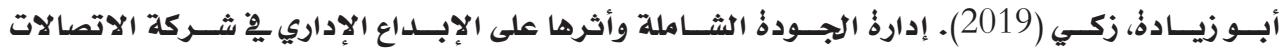

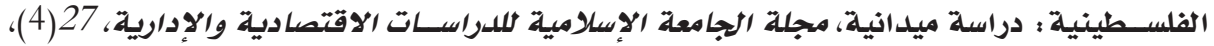
.128-95

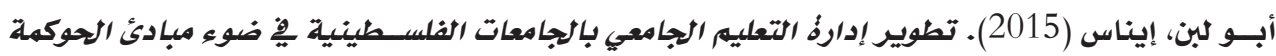

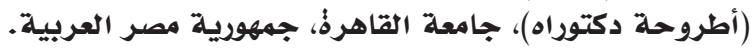

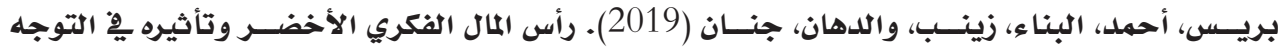

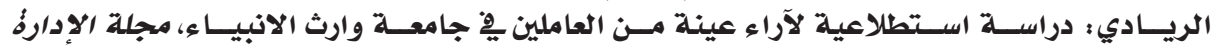

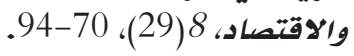

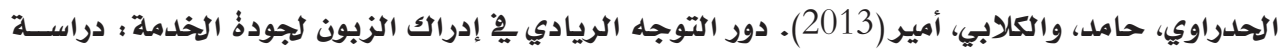

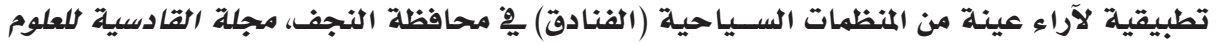

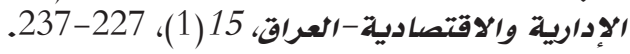

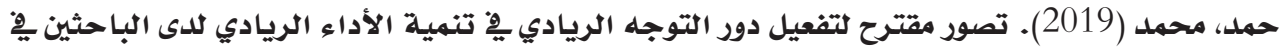

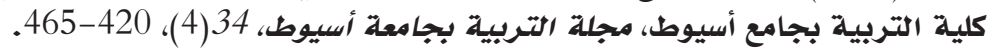

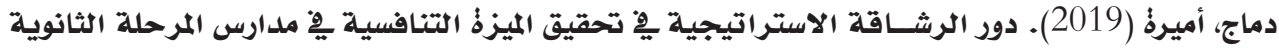

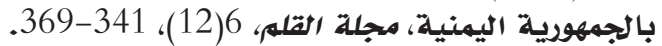

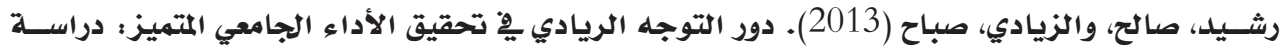

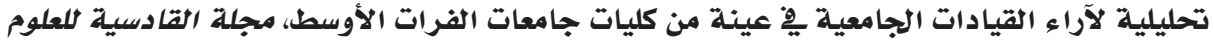

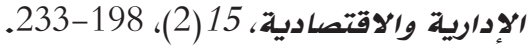

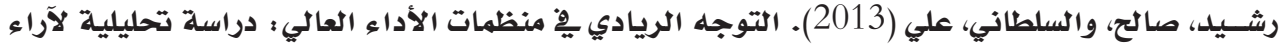

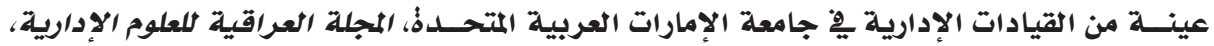
.33-1، (9) 38 


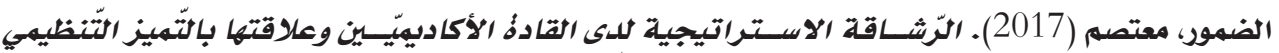

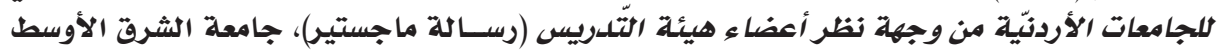

$$
\text { للدراسات العليا، الأردن. }
$$

عبــد الرزاق، رغــدان (2018). أنماط القيادذٌ وآثرها يِّ تحقيق الرشــاقة الاســتراتيجية، مجلة العلوم

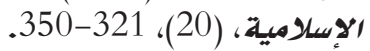

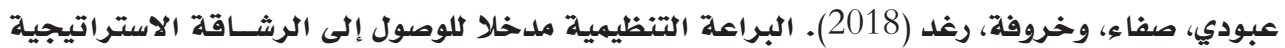

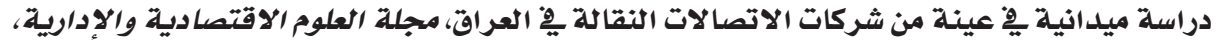

$$
\text { .258-240، (109)، } 24
$$

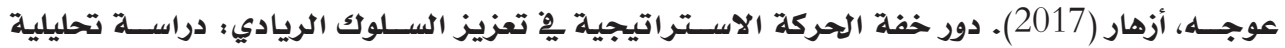

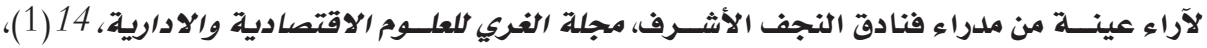

.305-219

الفقيه، منال (2018). دور الرثاقة الاستراتيجية فِ تحقيق الميزةٌ التنافسية للجامعات اليهنية، استرجع

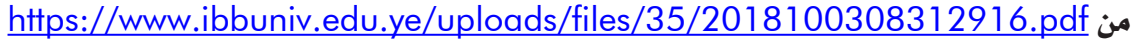

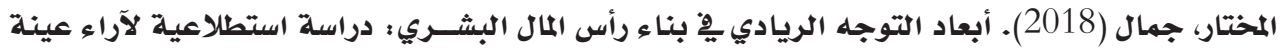
من القيادات الإدارية ِِِ مؤسسات الجامعة التقنية الشمالية يِّاء محافظة نينوى، مجلة تكريت للعلوم

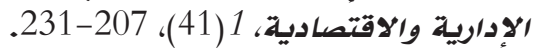

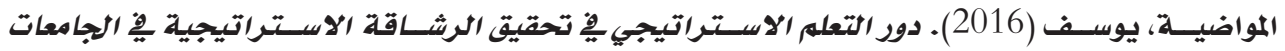

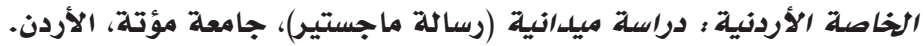

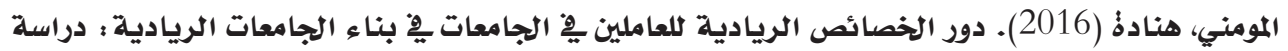
تطبيقية على الجامعات الأردنية الخاصدة، دراسات : العلوم الإداريية، 43(2013)، 813-825.

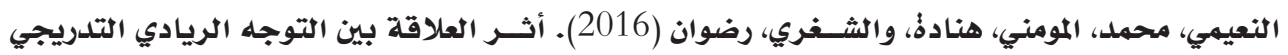

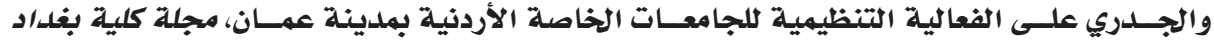
كلعلوم الوقتصادية الجامعة الفعالية، (48)، 23-56.

Al-Azzam, Z. F., Irtaimeh, H. J. A., \& Khaddam, A. A. H. (2017). Examining the mediating effect of strategic agility in the relationship between intellectual capital and introduction organizational excellence in Jordan Service Sector. Journal of Business, 6(1), 7-15.

Al-Dhaafri, H. S., Al-Swidi, A. K., \& Yusoff, R. Z. B. (2016). The mediating role of total quality management between the entrepreneurial orientation and the organizational performance. The TQM Journal, 28(1), 89-111.

Aliyu, M. S., Rogo, H. B., \& Mahmood, R. (2015). Knowledge management, entrepreneurial orientation and firm performance: The role of organizational culture. Asian Social Science, $17(23), 140-152$.

Amin, M., Thurasamy, R., Aldakhil, A. M., \& Kaswuri, A. H. B. (2016). The effect of market orientation as a mediating variable in the relationship between entrepreneurial orientation and SMEs performance. Nankai Business Review International. Nankai Business Review International, 7(1), 39-59.

Angela, M. M. (2015). Influence of strategic agility on competitive capability of private universities in Kenya (Doctoral dissertation). University of Nairobi, Kenya. 
زكي عبد المعطي أبو زيادةٌ إيناس موسى الزين

المجلد الرابع عشر العدد (50) 2021م إئاسن موسى الزين

Aqilat, H. (2019). The impact of strategic agility on the media reputation in the private jordanian universities. Journal of the Faculty of Education in Assiut University, 35(9).

Arief, M., Thoyib, A., Sudiro, A., \& Rohman, F. (2013). The effect of entrepreneurial orientation on the firm performance through strategic flexibility: A study on the SMEs cluster in Malang. Journal of Management Research, 5(3), 44-62.

Ayub, A., Arzu, F., Iftekhar, H., \& Hafeez, S. (2014). Entrepreneurial Call for Strategic Agility in Fast-Paced Business Environment. Acta Universitatis Danubius. OEconomica, 10(3), 146-154.

Bondzi-Simpson, P. E., \& Agomor, K. S. (2021). Financing public universities in Ghana through strategic agility: Lessons from Ghana institute of management and public administration (GIMPA). Global Journal of Flexible Systems Management, 22(1), 1-15.

Chan, J., \& Muthuveloo, R. (2020). Vital organisational capabilities for strategic agility: an empirical study. Asia-Pacific Journal of Business Administration, 12(3/4), 223-236.

Chavez, R., Yu, W., Jacobs, M. A., \& Feng, M. (2017). Manufacturing capability and organizational performance: The role of entrepreneurial orientation. International Journal of Production Economics, 184, 33-46.

Clercq, D., Dimov, D., \& Thongpapanl, N. T. (2010). The moderating impact of internal social exchange processes on the entrepreneurial orientationperformance relationship. Journal of Business Venturing, 25(1), 87-103.

Doz, Y. L., \& Kosonen, M. (2010). Embedding strategic agility: A leadership agenda for accelerating business model renewal. Long Range Planning, 43(2-3), 370-382.

Ejdys, J. (2016). Entrepreneurial orientation vs. innovativeness of small and medium size enterprises. Journal of Engineering, Project, and Production Management, 6(1), 13-24.

Elali, W. (2021). The importance of strategic agility to business survival during corona crisis and beyond. International Journal of Business Ethics and Governance, 4(2), 1-8.

Faiz, G \& Ahmad, F. (2015). The effect of entrepreneurial orientation on the organizational performance: A study on banks in Libya. The Journal of Social Sciences Research, 7(3), 25-31.

Feifei, Y. U. (2012). Strategic flexibility, entrepreneurial orientation and firm performance: Evidence from small and medium-sized business (SMB) in China. African Journal of Business Management, 6(4), 1711-1720. 
García-Villaverde, P. M., Rodrigo-Alarcón, J., Parra-Requena, G., \& Ruiz-Ortega, M. J. (2018). Technological dynamism and entrepreneurial orientation: The heterogeneous effects of social capital. Journal of Business Research, 83, 51-64.

Govender, D. (2020). The moderating role of strategic agility on the relationship between entrepreneurial orientation and organisational performance (Doctoral dissertation). University of Pretoria, South Africa.

Hair, J, Anderson, R., Tatham, R., \& Black, W. (2006). Multivariate data analysis ( $6^{\text {th }}$ ed.). New Jersey: Prentice Hall.

Hinkle, D., Wiersma, W., \& Jurs, S. (2003). Statistics for the behavioral sciences ( $5^{\text {th }}$ ed.). Boston: Houghton Mifflin Company.

Huang, K., Wang, K. Y., Kuo-Hisung, C., \& Yien, J. (2011). Revealing the effects of entrepreneurial orientation on firm performance: A conceptual approach. Journal of Applied Sciences, 7 7(16), 3049-3052.

Hughes, M., \& Morgan, R. E. (2007). Deconstructing the relationship between entrepreneurial orientation and business performance at the embryonic stage of firm growth. Industrial Marketing Management, 36(5), 651-661.

Ivory, S. B., \& Brooks, S. B. (2018). Managing corporate sustainability with a paradoxical lens: Lessons from strategic agility. Journal of Business Ethics, 148(2), 347-361.

Jalali, A., Jaafar, M., \& Ramayah, T. (2014). Entrepreneurial orientation and performance: the interaction effect of customer capital. World Journal of Entrepreneurship, Management and Sustainable Development, 10(1), 48-68.

Junni, P., Sarala, R. M., Tarba, S. Y., \& Weber, Y. (2015). The role of strategic agility in acquisitions. British Journal of Management, 26(4), 596-616.

Khavari, S., Arasteh, H. \& Jafari, P. (2016). Assessing the level organizational universities agility: Case study of Islamic Azad University in Mazandaran. Mediterranean Journal of Social Sciences, 7(3s2), 112-117.

Khorshid, S. (2018). The impact of strategic agility and organization emotional capabilities on university's entrepreneurship-orientation (Case study: Universities of Qom and Kashan Cities). Management in Islamic University, 14(6), 237-262.

Khoshnood, N. T., \& Nematizadeh, S. (2017). Strategic agility and its impact on the competitive capabilities in Iranian private banks. International Journal of Business and Management, 12(2), 220-229.

Kraus, S., Rigtering, J. P., Hughes, M., \& Hosman, V. (2012). Entrepreneurial orientation and the business performance of SMEs: a quantitative study from the Netherlands. Review of Managerial Science, 6(2), 161-182. 
زكي عبد المعطي أبو زيادةٌ إيناس موسى الزين

المجلد الرابع عشر العدد (50) 2021م إئاسن موسى الزين

Kropp, F., Lindsay, N. J., \& Shoham, A. (2006). Entrepreneurial, market, and learning orientations and international entrepreneurial business venture performance in South African firms. International Marketing Review, 23(5), 504-523.

Kundu, S. C., \& Rani, S. (2016). Female aspirant human resources' entrepreneurial orientation: a study in Indian context. Management Research Review, 39(2), 235-263.

Lee, L. Y., \& Tan, E. (2012). The influences of antecedents on employee creativity and employee performance: A meta-analytic review. Interdisciplinary Journal of Contemporary Research in Business, 4(2), 984-996.

Lewis, M. W., Andriopoulos, C., \& Smith, W. K. (2014). Paradoxical leadership to enable strategic agility. California Management Review, 56(3), 58-77.

Long, C. (2000). Measuring your strategic agility. Consulting to Management, $17(3), 25-28$.

Mavengere, N. (2013). Information systems role in strategic agility: A supply chain context (Doctoral dissertation). University Tampere, Finland.

Mukeriee, S. (2014). Agility: A crucial capability for universities in times of disruptive change and innovation. Australian Universities' Review, 56(1), 56-60.

Nkuda, M. O. (2017). Strategic agility and competitive advantage: Exploration of the ontological, epistemological and theoretical underpinnings. British Journal of Economics, Management \& Trade, 16(1), 1-13.

Olaleye, B., Anifowose, O., Efuntade, A., \& Arije, B. (2021). The role of innovation and strategic agility on firms' resilience: A case study of tertiary institutions in Nigeria. Management Science Letters, $17(1)$, 297-304.

Oni, O., Agbobli, E. K., \& Iwu, C. G. (2019). Entrepreneurial orientation and performance of small business in Vryburg region North West province South Africa. Journal of Reviews on Global Economics, 8, 63-71.

Osman, M. H., Rashid, M. A., Ahmad, F., \& Hussain, G. (2011). Entrepreneurial orientation: An overview of theory and insinuations for women-owned SMBs to model business performance in developing countries. Interdisciplinary Journal of Contemporary Research in Business, 3(3), 329-340.

Otache, I., \& Mahmood, R. (2015). Entrepreneurial orientation and performance of Nigerian banks: The mediating effect of teamwork. Mediterranean Journal of Social Sciences, 6(3), 406-414.

Pearce, J. A., Fritz, D. A., \& Davis, P. S. (2010). Entrepreneurial orientation and the performance of religious congregations as predicted by rational choice theory. Entrepreneurship Theory and practice, 34(1), 219-248. 
Porananond, D., \& Thawesaengskulthai, N. (2014). Risk management for new product development projects in food industry. Journal of Engineering, Project, and Production Management, 4(2), 99-113.

Prats, M. J., Siota, J., Gillespie, D., \& Singleton, N. (2018). Organizational agility. New York, NY: IESE Business School and Oliver Wyman.

Roy, R., \& Das, N. (2017). Proactive Entrepreneurial Characteristics of Science and Technology Students: An Empirical Study in Indian Context. Current Science, 113(9), 1692-1701.

Sekaran, Uma. (2006). Research methods for business: A skill building approach ( $6^{\text {th }}$ ed.). New York: John Wiley \& Sons Inc.

Tahmasebifard, H., Zangoveinezhad, A., \& Jafari, P. (2017). The role of entrepreneurial orientation in achieving agility capability. Journal of Applied Economics \& Business Research, 7(2), 137-156.

Tallon, P. P. (2008). Inside the adaptive enterprise: an information technology capabilities perspective on business process agility. Information Technology and Management, 9(1), 21-36.

Teoh, A. P., Lee, K. Y., \& Muthuveloo, R. (2017). The impact of enterprise risk management, strategic agility, and quality of internal audit function on firm performance. International Review of Management and Marketing, 7(1), 222-229.

Tikkanen, J. (2014). Dynamic capability influence on Strategic agility: A case study in energy conservation industry (Master thesis). University of Oulu, Finland.

Wiklund, J., \& Shepherd, D. (2005). Entrepreneurial orientation and small business performance: a configurational approach. Journal of Business Venturing, 20(1), 71-91.

Yeboah, M. A. (2013). Do auto artisans practice entrepreneurial orientation? Empirical evidence from the Cape Coast Metropolis, Ghana. International Journal of Development and Sustainability, 2(4), 2337-2353.

Yoon, H. (2012). The performance effects of entrepreneurial orientation: Evidence from South Korean start-ups. International Journal of Arts and Commerce, $7(4), 248-254$.

\section{Arabic References in Roman Scripts:}

Abdul-Razzaq, Raghdan (2018). Anmat alqiadat wathiriha fi tahqiq alrashaqat aliastiratiiiati, Majalat Aleulum Al'iislamiati, (20), 321-350.

Aboudi, Safaa, we Kharoufa, Raghad (2018). Albaraeat altanzimiat mdkhlaan lilwusul 'iilaa alrashaqat alastiratiijiat dirasatan maydaniatan fi eayinat min sharikat alaitisalat alnaqaalat fi aleiraqi, Majalat Aleulum Alaiqtisadiat Wal'iidariati, 24(109), 240-258. 
زكي عبد المعطي أبو زيادةٌ إيناس موسى الزين

المجلد الرابع عشر العدد (50) 2021م إئدم موسن

Abu Laban, Enas (2015). Tatwir 'iidarat altaelim aljamieii bialjamieat alfilastiniat fi daw' mabadi alhawkama (Utaruhat dukturah), Jamieat Alqahirati, Jumhuriat Misr Alearabiati.

Abu Ziada, Zaki (2019). Edarat aljawdat alshaamilat wa'athariha ealaa al'iibdae al'iidarii fi sharikat alaitisalat alfilastiniati: Dirasat maydaniatun, Majalat Aljamieat Al'iislamiat Lildirasat Alaiqtisadiat Wal'iidariati, 27(4), 95-128.

Al-Dhumur, Mutasim (2017). Alrrshaqt alastiratijiat ladaa alqadat alakadymyyn waealaqatiha balttmyz alttnzymy liljamieat alardnyt min wijhat nazar 'aeda' hayyat alttdrys (Risalat majistir), Jamieat Alshara Al'awsat Lildirasat Aleulya, Al'urdunn.

Al-Faqih, Manal (2018). Dawr alrashaqat aliastiratijiat fi tahqia almizat altanafusiat liliamieat alyamaniati, Aistariie min https://www.ibbuniv.edu.ye/uploads/files/35/2018100308312916.pdf

Al-Hadrawi, Hamed, wa Al-Kilabi, Amir (2013). Dawr altawajuh alriyadii fi 'iidrak alzubun lijawdat alkhidmati: Dirasat tatbiqiat lara' eayinat min almunazamat alsiyahia (alfanadiqi) fi muhafazat alnajaf, Majalat Alqadisiat Lileulum Al'iidariat Walaiqtisadiati-Aleiraqi, 15(1), 227-237.

Al-Momani, Hanada (2016). Dawr alkhasayis alriyadiat lileamilin fi aljamieat fi bina' aljamieat alriyadiati: Dirasat tatbiqiat ealaa aljamieat al'urduniyat alkhasati, Dirasati: Aleulum Al'iidariati, 43(2), 813-825.

Al-Mukhtar, Jamal (2018). Abaad altawajuh alriyadii fi bina' ras almal albashari: Dirasat aistitlaeiatan lara' eayinat min alqiadat al'iidariat fi muasasat aljamieat altaqniat alshamaliat fi muhafazat ninawaa, Majalat Tikrit Lileulum Al'iidariat Walaiqtisadiati, 1(41), 207-231.

Al-Muwadhia, Yousuf (2016). Dawr altaealum alastiratiiii fi tahqiq alrashaqat alastiratijiat fi aljamieat alkhasat al'urduniyati: dirasat maydania (Risalat majistir), Jamieat Mutata, Al'urdunn.

Al-Nuaimi, Muhammad, Al-Momani, Hanada, wa Al-Shugry, Radwan (2016). Athar alealaqat bayn altawajuh alriyadii altadrijii waljadarii ealaa alfaeaaliat altanzimiat liljamieat alkhasat al'urduniyat bimadinat eaman, Majalat Kuliyat Baghdad Lileulum Alaiqtisadiat Aljamieati, (48), 23-56.

Auja, Azhar (2017). Dawr khifat alharakat alastiratijiat fi taeziz alsuluk alriyadii: dirasatan tahliliatan lara' eayinat min mudara' fanadiq alnajaf al'ashrafi, Majalat Algharii Lileulum Alaiqtisadiat Waladariati, 14(1), 219-305.

Bress, Ahmed, Al-Binaa, Zainab, wa Al-Dahhan, Jinan (2019). Ras almal alfikrii al'akhdar watathiruh fi altawajuh alriyadii: Dirasatan aistitlaeiat lara' eayinat min aleamilin fi jamieat warith alainbia'i, Majalat Al'iidarat Walaiqtisadi, 8(29), 70-94. 


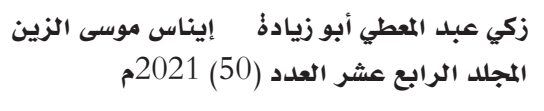

Dammai, Amira (2019). Dawr alrashaqat aliastiratiijat fi tahqiq almizat altanafusiat fi madaris almarhalat althaanawiat bialjumhuriat alyamaniati, Majalat Alqalama, 6(12), 341-369.

Hamad, Mohammed (2019). Tasawur muqtarah litafeil dawr altawajuh alriyadii fi tanmiat al'ada' alriyadii ladaa albahithin fi kuliyat altarbiat bijamie 'asyuti, Majalat Altarbiat Bijamieat 'Asyut, 34(4), 420-465.

Rashid, Saleh, wa Al-Sultani, Ali (2013). altawajuh alriyadiu fi munazamat al'ada' aleali: Dirasat tahliliat lara' eayinat min alqiadat al'iidariat fi jamieat al'iimarat alearabiat almutahidati, Almajalat Aleiraqiat Lileulum Al'iidariati, 38(9), 1-33.

Rashid, Saleh, wa Al-Ziyadi, Sabah (2013). Dawr altawajuh alriyadii fi tahqia al'ada' aljamieii almutamayiza: Dirasat tahliliat lara' alqiadat aljamieiat fi eayinat min kuliyaat jamieat alfurat al'awsat, Majalat Alqadisiat Lileulum Al'iidariat Walaiqtisadiati, 15(2), 198-233. 